\title{
AUTOMATION IN STRUCTURAL HEALTH MONITORING OF TRANSPORT INFRASTRUCTURE
}

Lihai Zhang*, Nilupa Herath, Babar Nasim Khan Raja, Shilun Chen, Saeed Miramini, Colin Duffield

Department of Infrastructure Engineering, University of Melbourne, VIC 3010, Australia

*Email: lihzhang@unimelb.edu.au.

\begin{abstract}
Roads are among the most important assets in the world. Road structure improvements make a crucial contribution to economic development and growth and bring important social benefits. Automation in structural health monitoring allow the accurate prediction of ongoing damage caused by long-term traffic loading. This permits optimal road structure management and ensures the longevity and safety of road structures. This chapter discusses a variety of advanced automation techniques in structural health monitoring of road structures, such as data acquisition, data processing, and life-cycle assessment. It demonstrates that the implementation of automation in road asset management can increase the productivity and extend the service life of road structures, and enhance the durability of crucial road structures and increase transport infrastructure sustainability.
\end{abstract}

\section{Automation in inspection}

\subsection{Introduction}

The implementation of damage identification strategy for assessing civil, mechanical, and aerospace engineering infrastructure is called structural health monitoring (SHM). Damage is defined as any change in material or geometric properties that can adversely affect the current or future performance of the infrastructure system, including boundary conditions and connectivity. (Farrar and Worden, 2007). Bridges are an important component of the civil infrastructure and a huge investment is required for their construction and maintenance. A bridge that is currently in use is subjected to constant and potentially destructive damage due to heavy repetitive traffic loading and certain natural hazards, such as earthquakes, floods, and other environmental effects. The ageing and degradation of bridges can lead to structural and/or functional failures.

The 2017 data from the American Society of Civil Engineers (ASCE, 2017) lists a total of 614,387 bridges in the national bridge inventory, with an average bridge being 43 years old. Therefore, an increasing number of bridges need rehabilitation or will soon need retirement as most of bridges in the US are designed for a 50-year life span. A total of $9.1 \%$ of all US bridges are already categorised as structurally deficit, and requiring significant maintenance, rehabilitation, or replacement. Figure 1.1 shows the 
percentage of US bridges by age. The estimated backlog of rehabilitation projects for national bridges is around USD 123 billion. Similarly, as per the Canadian Infrastructure Report Card (2016), over $26 \%$ of the bridges in Canada are at below fair condition.

\section{America's bridges by age}

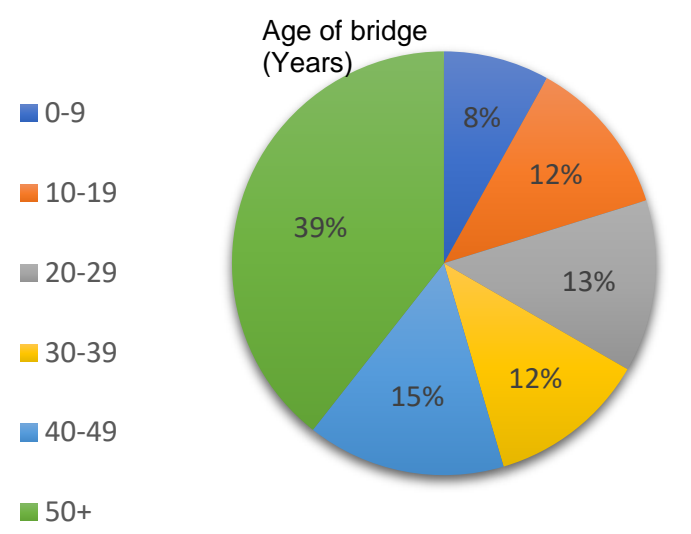

Figure 1.1: American bridges by age (ASCE, 2017)

In Australia, there are approximately 33,000 bridges, of which 11,308 bridges are in Victoria, most of which were built in 1960 . Over $60 \%$ of Victorian bridges are made of concrete and over $50 \%$ of bridges in Australia are considered in a fair $(40 \%)$ or poor condition (15\%) (Rashidi and Lemass, 2011, Vines, 2010).

The failure of the pin-connected suspension bridge, e.g., the Silver Bridge in Ohio, US, in 1967, due to a crack in one of the eye bars alerted the authorities to the deteriorating condition of the national infrastructure and the need for routine inspection. Consequently, the National Bridge Inspection Program (NBIP) was first initiated in the US in 1970 (Fu, 2005). By using the NBIP, over time, a bridge might be rated as structurally deficient due to several factors such as the mechanical behaviour of the concrete, traffic loading, ageing condition, and other factors.

Bridge condition data are fundamental to a bridge management system (BMS). The data are collected at regular intervals and analysed to regulate the optimum fund allocation for new construction and the conservation and rehabilitation programs for existing structures. A substantial part of the bridge maintenance costs is for the repair and replacement of concrete decks only (Gucunski and Council, 2013). Around 60\% of bridge maintenance strategies rely on regular inspection data for accurate prediction of bridge condition. Typically, the following five-step procedure is used to assess bridge health (Pan et al., 2009):

1. Condition evaluation;

2. Forecasting deterioration; 
3. Defining a suitable maintenance strategy;

4. Prioritising the maintenance;

5. Optimising resource allocation.

\subsection{General type of bridge inspection}

In order to ensure the structural integrity and level of service, different types of inspections are carried out during the service life of a bridge. These inspections include routine inspections, overall structure condition inspections, detailed or in-depth inspections, and special inspections. The selection of the type of bridge inspection depends upon the existing condition report and age of the structure. In Australia, these inspection programs are categorised into several different levels, depending on the state authority. The Victorian and Queensland inspection manuals contain three levels of inspections, described as Levels 1, 2, and 3, whereas the New South Wales bridge inspection manual has four levels (Sonnenberg, 2012, Fu, 2005).

\subsubsection{Routine inspection}

This inspection is normally completed in conjunction with the routine maintenance work of road reserves. The entire bridge and its adjacent structural components are assessed during this inspection and the main purpose is to check the general serviceability of structure and for any obvious sign of distress or damage that can affect the immediate safety of the road user. The inspection report also includes a recommendation for any future inspection and the immediate measures that should be taken to ensure road user safety.

\subsubsection{Structural condition inspection or damage inspection}

This type of inspection is usually carried out visually to assess the condition of the different bridge components and the whole structure. The structural defects and components that need detailed inspection are identified. Sometimes, a photographic record is obtained. An estimate for the maintenance budget and effectiveness of any past maintenance treatment is also assessed.

\subsubsection{Detailed or in-depth inspection}

This is a detailed engineering inspection that normally includes field testing as well as theoretical analysis. This is usually performed to collect the information regarding the integrity and safety of a specific element of the bridge. It provides an improved knowledge of service performance of the individual components and the load rating. This type of inspection most often requires specific tools and equipment either for accessibility or for further non-destructive testing investigations.

\subsubsection{Special inspection}

This refers to the investigation of a specific element with previously known or suspected deterioration conditions. Scour monitoring, foundation settlement, and bearing corrosion are some examples that require a special bridge inspection. 


\subsection{Frequency of bridge inspections around the world}

The summary of bridge inspection frequency for the US (FHWA, 2013), Japan (NEXCO-West), European countries (Everett et al., 2008), and Australia (Andrew Sonnenberg, 2014 ) is presented in Table 1.1.

\section{Table 1.1: Bridge inspection frequency around the world}

\begin{tabular}{|c|c|c|}
\hline Country & Inspection type & Frequency \\
\hline US & $\begin{array}{l}\text { General inspection }(83 \%) \\
\text { Bridges that need close monitoring (12\%) } \\
\text { Bridges that are in good condition (5\%) }\end{array}$ & $\begin{array}{l}\text { Every } 2 \text { years } \\
\text { Annually } \\
\text { Maximum on } 48 \text {-month cycle }\end{array}$ \\
\hline Japan & $\begin{array}{l}\text { First inspection after bridge construction } \\
\text { Periodic thereafter }\end{array}$ & $\begin{array}{l}\text { Every } 2 \text { years } \\
\text { Every } 5 \text { years (depending } \\
\text { upon bridge condition) }\end{array}$ \\
\hline Finland & $\begin{array}{l}\text { General inspection (primary inspection) } \\
\text { Large bridges }\end{array}$ & $\begin{array}{l}\text { Every } 5 \text { years } \\
\text { Every } 8 \text { years (depending } \\
\text { upon bridge condition) }\end{array}$ \\
\hline Denmark & Principal inspection (visual) & $\begin{array}{l}\text { Every } 5.5 \text { years (average) } \\
\text { (determined by the inspector } \\
\text { depending upon bridge } \\
\text { condition) }\end{array}$ \\
\hline Sweden & $\begin{array}{l}\text { Major inspection } \\
\begin{array}{l}\text { Bridges need special consideration } \\
\text { (deteriorated) }\end{array}\end{array}$ & $\begin{array}{l}\text { Every } 6 \text { years (determined by } \\
\text { inspector) } \\
\text { Frequently }\end{array}$ \\
\hline Norway & $\begin{array}{l}\text { Major inspection } \\
\text { General inspection }\end{array}$ & $\begin{array}{l}\text { Every } 6 \text { years (minimum) } \\
\text { Annually }\end{array}$ \\
\hline France & $\begin{array}{l}\text { Annual visual inspection } \\
\text { Detailed visual inspection } \\
\text { Engineered inspection }\end{array}$ & $\begin{array}{l}\text { Annually } \\
\text { Every } 3 \text { years } \\
\text { Every } 3-9 \text { years (determined } \\
\text { by inspector based on bridge } \\
\text { condition report) }\end{array}$ \\
\hline Germany & $\begin{array}{l}\text { Minor inspection (visual) } \\
\text { Major inspection }\end{array}$ & $\begin{array}{l}\text { Every } 3 \text { years } \\
\text { Every } 6 \text { years (first major } \\
\text { inspection performed before } \\
\text { opening the structure for } \\
\text { traffic and second inspection } \\
\text { before the end of guarantee } \\
\text { period) }\end{array}$ \\
\hline Australia & $\begin{array}{l}\text { Routine inspection } \\
\text { Damage or condition inspection } \\
\text { Detailed (in-depth) inspection }\end{array}$ & $\begin{array}{l}\text { Every } 6-12 \text { months } \\
\text { Every } 2 \text { years (average) } \\
\text { As required }\end{array}$ \\
\hline
\end{tabular}




\section{Automation in data processing for external defects}

In this section, the common external defects on transport infrastructure assets will be discussed in detail. Transport infrastructure assets mainly consist of bridges, roads, and tunnel structures. During their servicing periods, defects and problems with these structures will occur over time due to both internal and external factors. Some defects are exposed on the surface of structures, but others exist underneath the surface.

For bridge structures, cracking, leaching, and scaling are typical defects that are caused by shrinkages, loading, corrosion of reinforcement, temperature changes, and chemical attacks on the surface of bridge structures (Yehia et al., 2007). More severe surface defects, including spalling, honeycombing, and delamination, can directly cause problems with the structures' integrity as well as their performance (Ryall, 2001). For road structures, visible defects are located on the surface of the pavement. These defects contain ravelling, upheaval, shoving, rutting, depressions, potholes, and cracking distress. The main cracking distress is classified into three types: longitudinal, transverse, and miscellaneous cracks (Oliveira and Correia, 2008). For tunnel structures, major surface defects include lining cracks, leakage, steel corrosion, and lining void that will reduce the capacity of lining structure, and they can even cause further crack propagation (Wang et al., 2018). By detecting, identifying, and assessing different types of defects and their negative impacts on the external surface of transport infrastructure and the structures' performance, one can help to maintain a consistent structural health and performance throughout its design life.

\subsection{Conventional and automatic data acquisition approach}

Currently, existing data acquisitions and structural inspection for transport infrastructures are mainly based on manual inspections and semi-automatic inspections. For bridge structures, the external defects on the surface are typically investigated by using a bridge inspection vehicle stopping on a bridge deck with a long mechanical arm that can extend under the bridge deck. Inspectors stand on the platform of the mechanical arm to conduct the external surface inspection. For road structures, the highway pavement distress can be detected by an inspection vehicle that carries a camera and laser technology. The road inspection is semi-automatic with drivers in a vehicle moving at a relatively slower speed than the traffic. For tunnel structures, the external defects on the tunnel lining concrete panels are investigated by an inspection vehicle that is modified with a mechanical arm and platform that carries inspectors on board. Those external defects can be visually detected by inspectors (Chang et al., 2003).

Conventional visual inspections have limitations and disadvantages as they are labour-intensive, time-consuming, and costly. Hence, a new and advanced technique using an unmanned aerial vehicle (UAV) has been widely adopted internationally to complete images taken during the external surface detection process. When using UAVs for external defects detection on infrastructures, risk of work injuries for inspectors can be reduced. Also, application of UAV can reduce costs by reducing the labour and time (Zhang et al., 2019). Moreover, there is no need to close the road to 
traffic in some situations. The use of UAV allows one to conduct non-destructive techniques for external defects detection (Metni and Hamel, 2007). The most important aspect, the data acquisition stage, can be fully automated with automatic UAV flying, automatic UAV image taking, and automatic image transferring to a personal computer. Figure 2.1 shows an unmanned aerial and vehicle based automatic bridge inspection conducted by the University of Melbourne.

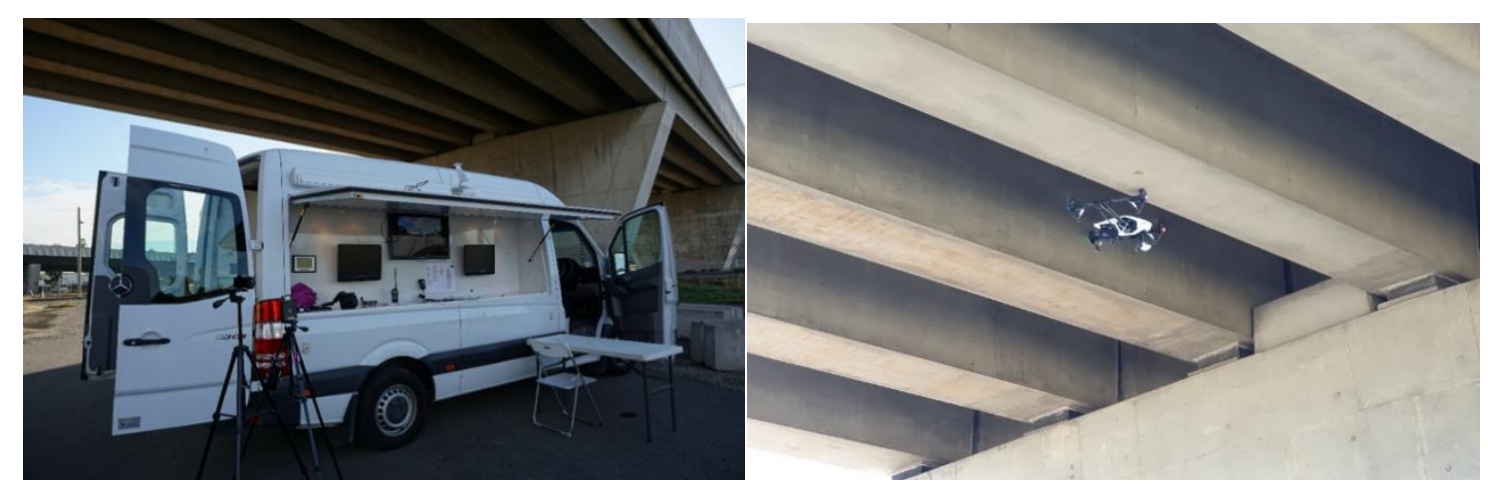

Figure 2.1: Unmanned aerial vehicle-based automatic bridge inspection and data acquisition

\subsection{Computer vision (CV)-based health assessment}

Computer vision (CV)-based health assessment can be defined as a process of analysing images for condition assessment of bridges. The routine structural damage inspection of bridges around the world is carried out by manual visual inspection (Table 1.1) and is probably the only appropriate evaluation method of structural assessment (Abdel-Qader et al., 2003). During a routine inspection, it is mandatory to identify the necessary measures and record information related to the defects and damage, like spalling, delaminations, bar exposure, rusting, staining, cracking, distortion, wear and tear, abrasion, scouring, and settlement. Similarly, the defects in non-structural elements, such as approach ways, wing walls, guide walls, and railing, are also monitored and recorded. In addition to these defects, monitoring the bearings and corrosion is recommended; irrespective of the bridge type and usage (Koch et al., 2015a). This data collection is necessary to determine the condition rating of the existing structures. Depending on the condition of the elements, the condition rating is categorised on a scale from 1 to 4 (Good, Fair, Poor, and Severe) (AASHTO, 2013, Vicroads, 2014). Typically, condition assessment is manually performed by a trained/certified inspector at regular intervals or post-disaster. Visual inspections are always subjective and can produce unreliable results (Moore et al., 2001).

As the frequency of routine inspection of bridges is rather high, it is time-consuming and uneconomical for the bridge management authorities to manually inspect and manage a large number of bridge structures. Currently, a lot of research studies have being carried out to automate visual inspection by using CV methods. Normally, the 
digital photos of bridge elements are taken and processed from different image processing techniques to automate damage detection. Much of the research has been focused on cracks identification and quantification (Jahanshahi et al., 2009, AbdelQader et al., 2003, Yamaguchi et al., 2008, Yamaguchi and Hashimoto, 2010, AbdelQader et al., 2006, Prasanna et al., 2012, Adhikari et al., 2013). Some research studies considered the rusting of steel elements and spalling or delaminations of reinforced concrete elements (German et al., 2012, Adhikari et al., 2013).

The CV-based damage detection has largely focused on visible damage/defects in a structure. The target is to achieve a fully automated system that can detect and classify the defects according to current BMSs.

\subsection{Automatic digital image data processing techniques}

After introducing the automatic data acquisition by using UAV, the next step is to automatically process the collected data with CV-based techniques. Nowadays, application of digital image processing (DIP) techniques seem promising for automatic external cracking identification on concrete and asphalt surfaces for bridge, road, and tunnel structures.

Digital image processing was developed as the advantageous crack assessment technique. The primary advantage of DIP is its repeatability, versatility, and the preservation of original data precision. These characteristics make DIP a useful technique to deal with the substantial amount of image information. The applications of DIP in areas related to automatic crack detection are generally aimed at solving the problems arising from subjective crack inspection and ineffective data collection and processing.

Several methods for automated crack identification have been studied and edge detection has potential in crack detection (Ellenberg et al., 2016). The edges in an image refer to the points where the brightness shows a critical jump (Chaganti, 2017). Hence, edge detection is the process of defining and locating those points with sharp discontinuous luminance (Chaganti, 2017). It is a common technique used in image processing and has a significant advantage with respect to effectively reducing image data to useful and desired information (Tsai et al., 2010). It has been shown that edge detection can be achieved by processing an image in the spatial, frequency, or timefrequency domains.

In spatial domain techniques, all the computation and operations are completed on the adjacent pixels of image (Gonzalez and Woods, 2008). The familiarised edge detection techniques such as Sobel and Canny are mainly based on gradients (Bhardwaj and Mittal, 2012). The gradient method focuses on finding the maximum and minimum intensity in the first derivative of the image. A sudden jump of intensity in some direction is presented by the angle for the gradient vector found at the edge pixels (Bhardwaj and Mittal, 2012). Sobel is a discrete differentiation operator most commonly used for its simplicity and speed when compared to other complicated algorithms (Abdel-Qader et al., 2003). It is based on the spatial gradient and is used for computing an approximate value of gradient of image intensity function for edge detection (Bhuvaneswari and Dr, 2014). 
The Canny operator is a convolution filter of Sobel. Although it is more complicated when compared with the traditional detector, it is more powerful (Canny, 1986). The principle of the Canny edge detector is to search for the partial maximum value of image gradient that counts the derivative of Gauss filter (Davies, 2005). It then uses Hysteresis thresholding that defines two thresholds, Thigh and $T_{\text {low, }}$ for detecting edges. $\left.\operatorname{MnMS}_{\text {N }} \mathrm{x}, \mathrm{y}\right)$ refers to the output of the non-maxima suppression. A pixel with $\mathrm{M}_{\mathrm{NMS}}(\mathrm{x}$, $y)>$ Thigh is called strong, whereas for pixels with $M_{\text {NMS }}(x, y)<$ Tlow would be discarded. Remaining pixels are identified as candidates, which means they are not output unless connected with a strong pixel.

In frequency domain techniques, the fast Fourier Transform is a frequency-based, discrete transformation that is an optimal algorithm for machine calculation (AbdelQader et al., 2003). It has a wide range of applications in the engineering world. The slowest varying frequency component corresponds to the average gravel level of an image, while the higher frequencies correspond to faster grey level changes in the image such as edges and noise (Gonzalez and Woods, 2008). To determine whether an abrupt change is noise or edges, a threshold is required to be given after performing the Fast Fourier Transform (FFT) (Gonzalez and Woods, 2008).

In time-frequency domain techniques, Fast Haar Transform (FHT) is introduced. The basic functions of FHT are Haar functions, considered to be the simplest and oldest orthonormal wavelets (Gonzalez and Woods, 2008). These forms are used in many methods of discrete image processing. The FHT is defined by computing running averages and differences via scalar products with scaling signals and wavelets (Davies, 2005).

With the help of two filters, the FHT firstly separates the image into low-frequency and high-frequency parts, followed by isolating the high-frequency coefficients. These high-frequency components correspond to the edges. Figure 2.2 shows the process of applying these four techniques for automatic image processing. Figure 2.3 illustrates the processing results for a sample concrete cracking image on a bridge deck by using the four different techniques.

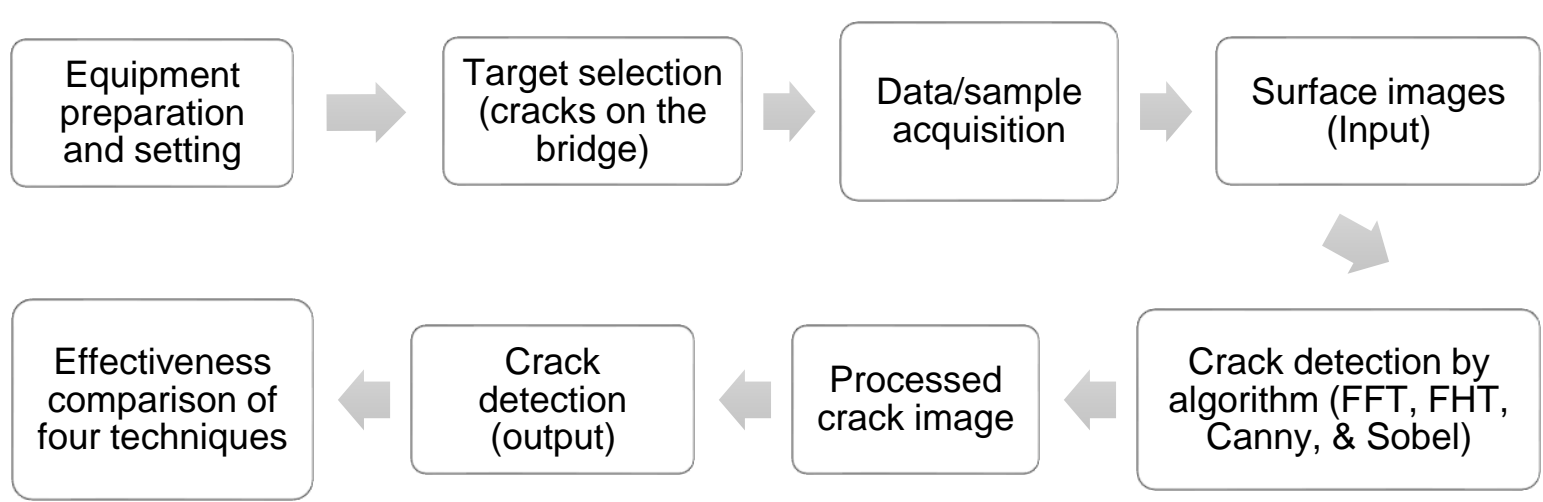

Figure 2.2: Overall process of automatic crack detection using digital image processing techniques 


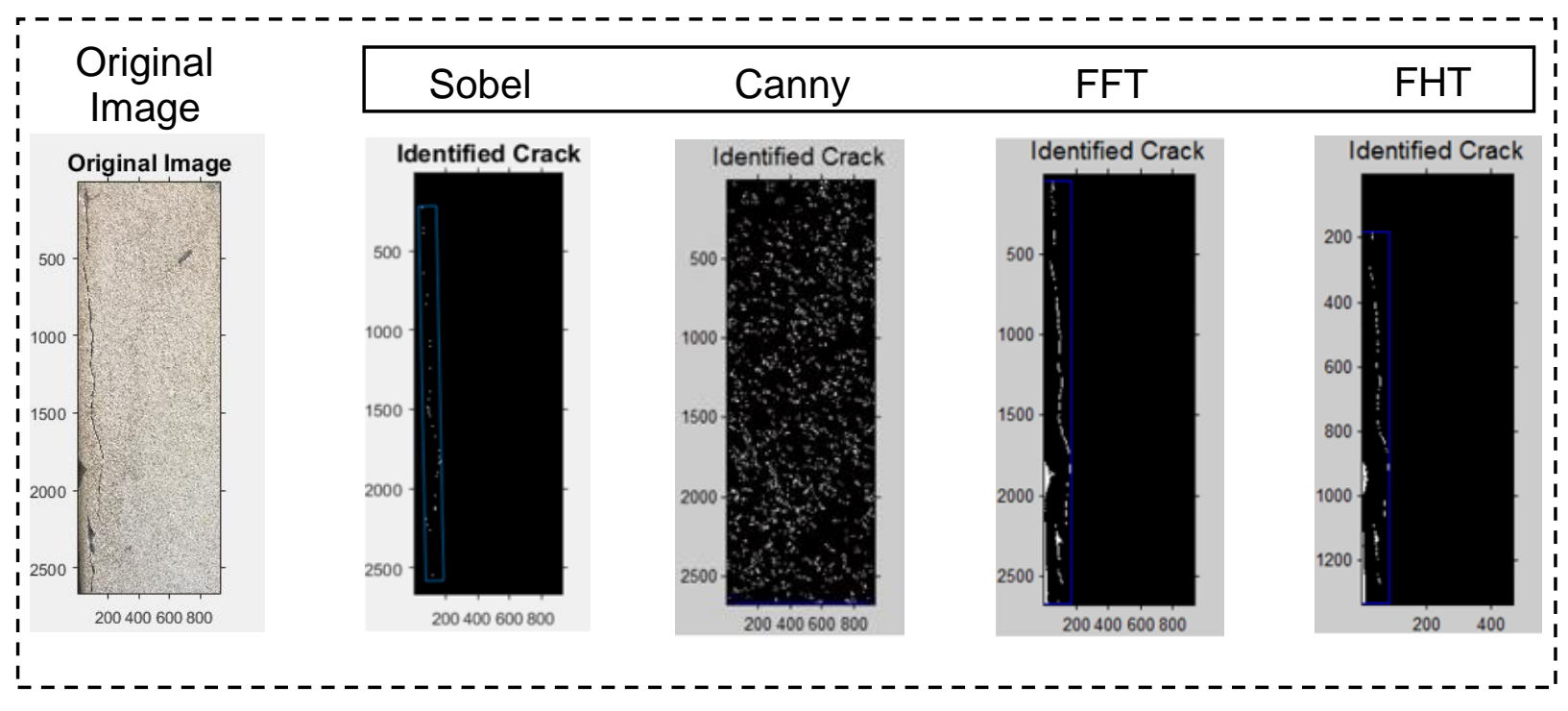

Figure 2.3: Results of automatic concrete cracking image processing using different algorithms

Based on the summary of the four edge detection techniques, they can be regarded as reliable and traditional techniques for automated crack detection by localising the borders of cracking pixels in images. However, there are still limitations if the original images contain noise that will influence the accuracy of crack detection.

\subsection{Innovative techniques for concrete image processing}

By considering the limitations of applying edge detection techniques, nowadays, there are innovative image processing techniques with an additional filtering and morphology process to improve the crack identification performance. (Fujita et al., 2011) proposed an automatic crack detection technique for "noisy" concrete surface images. There are two pre-processing steps and two detection steps in this technique. The use of a median filter to remove shadings from concrete images is the first preprocessing step. The second step is to use a multi-scale line filter with Hessian matrix to emphasise cracks from stains. After the pre-processing stage, probabilistic relaxation is firstly applied to detect cracks. Next, locally adaptive thresholding is used to detect fine cracks. This proposed technique shows high accuracy of crack detection based on 60 sample images. The schematic diagram of the proposed techniques developed by Fujita and Hamamoto (2011) is shown in Figure 2.4. 


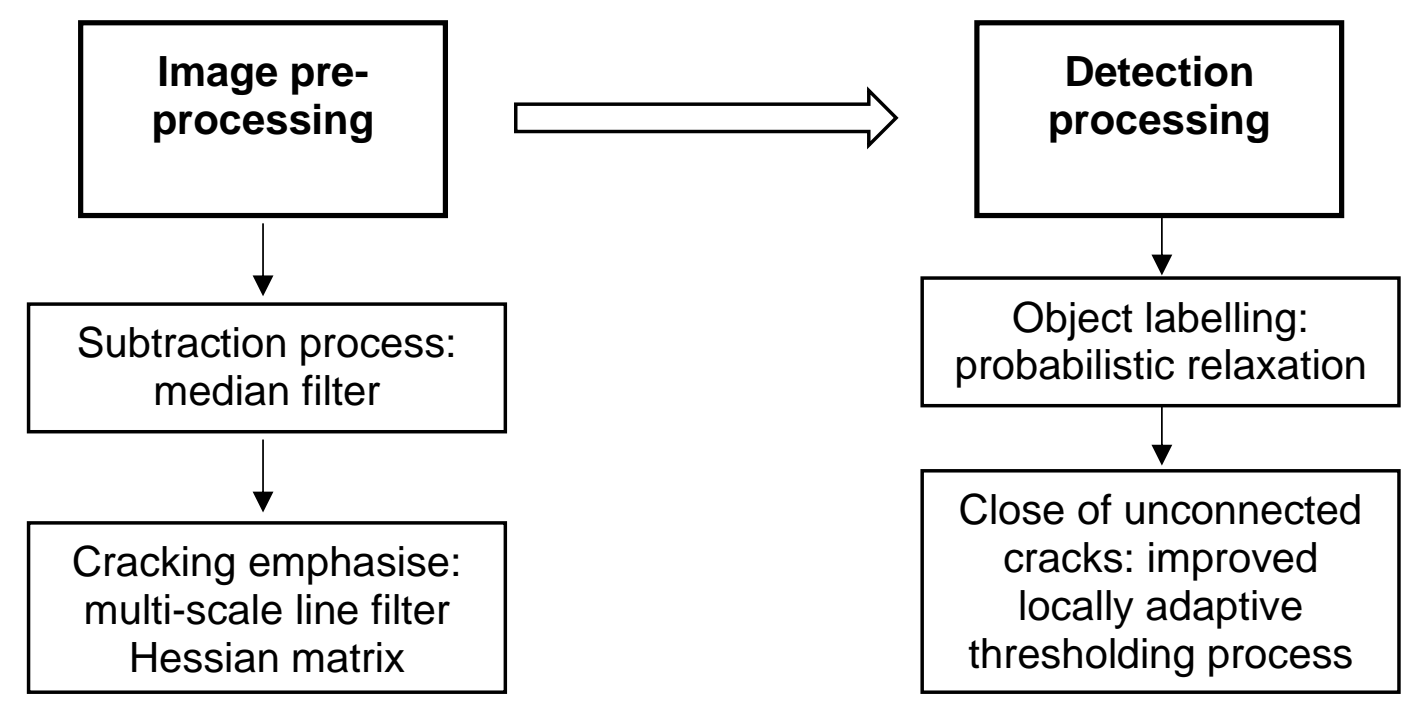

Figure 2.4: Proposed techniques of automatic crack detection by Fujita and Hamamoto (2011)

Lee et al. (2013) and Kim et al., (2019), developed an image processing technique for automatic crack detection and analysis based on the digital image of concrete surface. The first step is to apply a morphological technique to successfully correct the nonuniform brightness of the background of images. The next step is to apply a local binarisation process and double extraction process to accurately detect cracks from conditions of meaningless objects, textile background, and stains. The final step is to use a specific algorithm based on an artificial neural network (ANN) to calculate crack width, length, and orientation. The results have been validated to show accuracy of crack detection and analysis by using this technique in practical applications (Lee et al., 2013).

Lee et al., (2013) and Kim et al., (2019) are not the only researchers who developed an automatic image processing technique. A research group from Japan also generated an automatic image processing technique using multiple sequential image filters. They developed an image filter to first detect major cracks with genetic programming. Second, residual noise elimination and detection of indistinct cracks are conducted via an iterative application of image filtering of the surrounding area of the cracks. Finally, the width and length of cracks can be calculated based on the spatial derivatives of the brightness patterns. Their results show that the speed of identifying the best multi-sequential image filter is less than one-tenth of the speed of other conventional methods, and the accuracy of detection of cracks from various image conditions is highly improved by using two iterative methods for applications of image filters. Further, not only is their processing technique able to effectively calculate crack width and length, but the speed of automatic image processing of extracting crack information is fast with only $10 \mathrm{~s}$ processing time for a 1.5 million-pixel image running on a personal computer. However, the condition of concrete surface and crack types are considered the limitations of the proposed method developed by the Japanese research group (Nishikawa et al., 2012) as shown in Figure 2.5. 


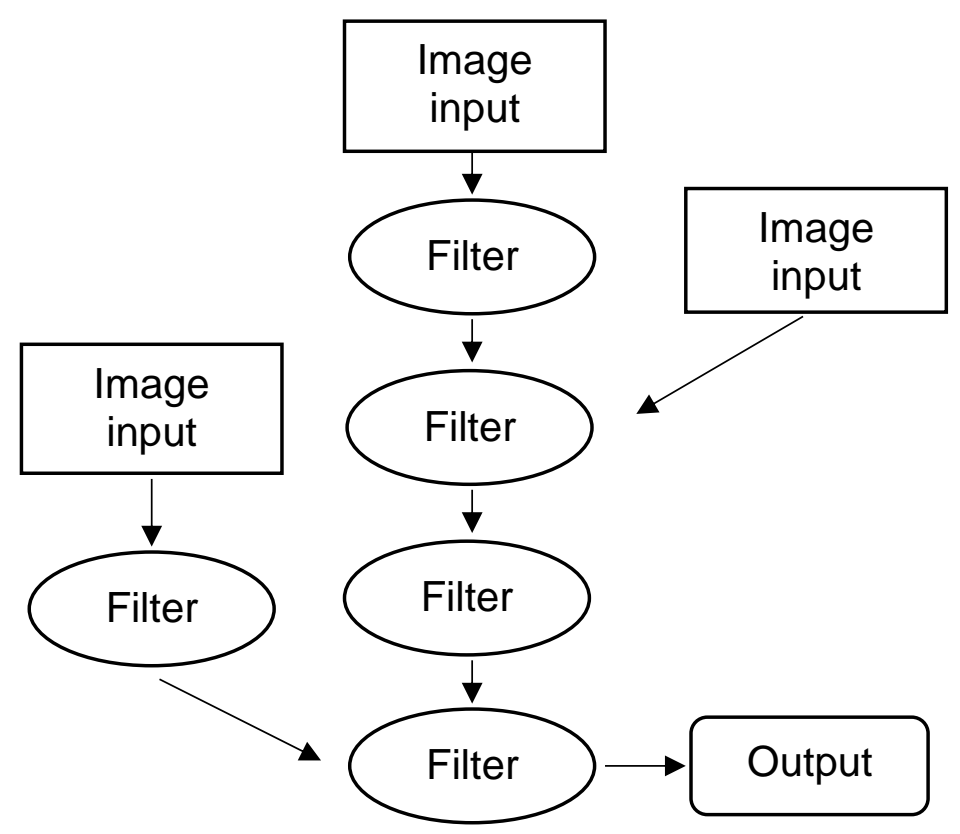

Figure 2.5: Concept of multiple sequential image filters applied in Nishikawa et al.'s (2012) study

However, the difficulty of distinguishing images containing cracks or crack-like noise patterns still exists (Kim et al., 2019). With the innovation of automatic DIP and image recognition techniques, the performance of crack identification under conditions of rough surface with stains, lumps, shadows, and holes is enhanced by using machine learning (ML) algorithms. In Moon and Kim's (2011) paper, they apply ANN for image classification after image processing. The first step uses the image filter, subtraction, and morphological operation to detect the crack and obtain crack information. In the second step, backpropagation neural network is adopted to automatically classify images to distinguish images with cracks and images with dark dirt only. In the process, a multi-layer ANN is used to replace human intelligence. The visual classification of images becomes a computer-based automatic classification. The manual classification results of images are treated as the target data values in the training process based on backpropagation neural network algorithms. Moon and Kim (2011) show that accuracy of cracking image and non-cracking image classification is up to $92 \%$ by using ANN based on 120 testing sample images and 105 training sample images (Figure 2.6) (Moon and Kim, 2011) (Moon and Kim, 2011). 


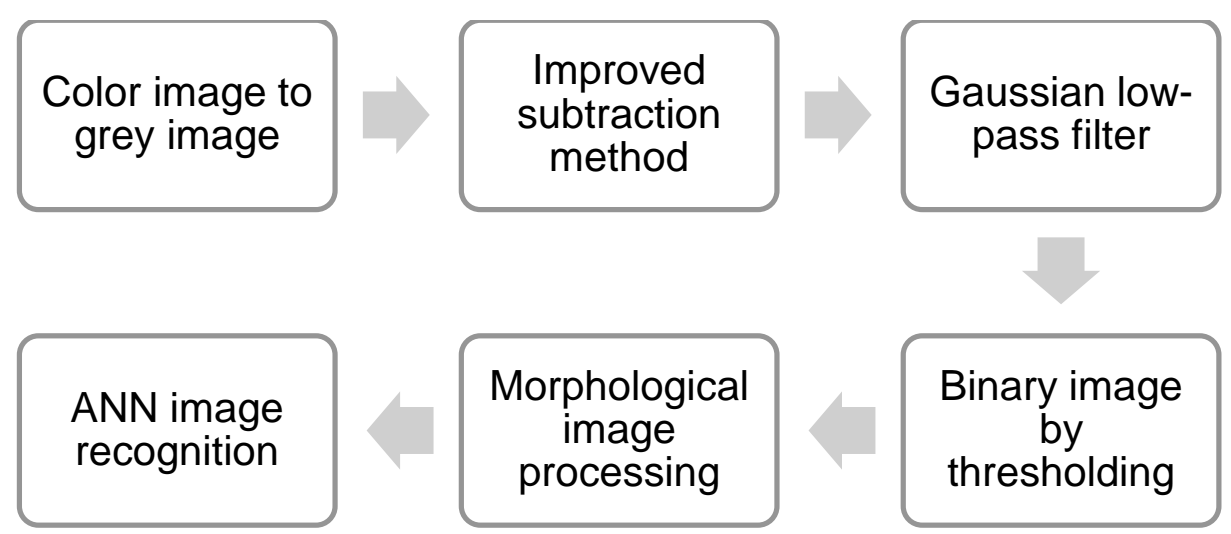

Figure 2.6: Overall process of crack recognition using artificial neural network (ANN) algorithm in Moon and Kim (2011) study

Another ML-based technique, developed by Kim et al. (2019), can classify cracks and non-cracking patterns that cannot be distinguished by other existing image processing algorithms. In their study, a framework based on crack candidate regions (CCRs) for crack identification is established. Concrete surface images with cracks and noncracks are prepared in the training stage. After generating CCRs, the speeded-up robust features (SURF)-based method and the convolutional neural network (CNN)based method are used to extract cracking information. The results show that the proposed framework for crack identification based on ML can effectively classify the images with cracks and non-cracking noise of concrete surface (Figure 2.7) (Kim et al., 2019).

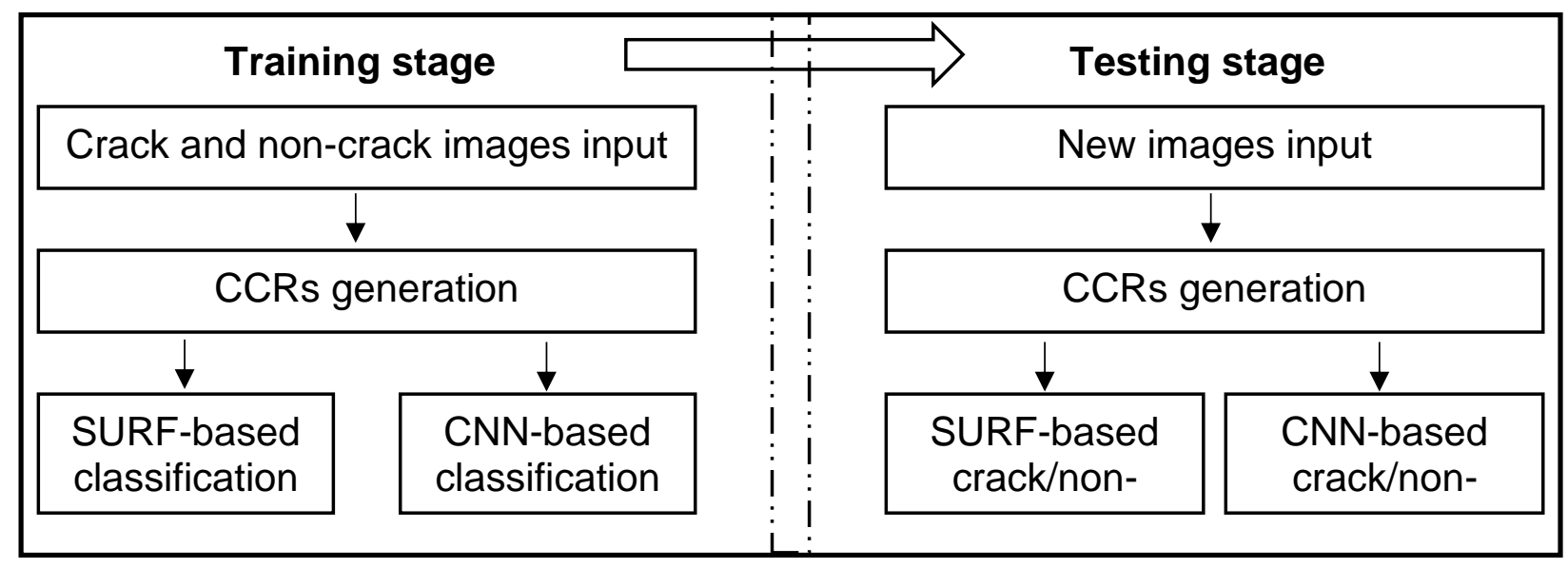

Figure 2.7: Proposed method of concrete crack classification in Kim et al., (2019) study using machine learning 


\subsection{Innovative techniques for pavement image processing}

The automatic detection of asphalt pavement distress from digital images of pavements requires more pre-processing of images when compared with the image processing for concrete surface. The asphalt pavement images contain more noise, and weather conditions as well as shadow influence increases the difficulties of image processing (Koch (Koch et al., 2015b). In Zou et al.'s (2012) research, a fully automatic technique for crack detection from asphalt pavement images was developed.

To overcome the shadow effect from the real images, a new geodesic-removal algorithm was developed to remove the shadow on the image and improve the contrast. Then, by adoption of the perceptual cues of proximity and continuity, a tensor voting technique has been applied to establish a crack probability map. To complete the final crack curves, the minimum spanning trees are constructed to find the connections of undesired edges in this tree and sample crack seeds. Based on 206 pavement images containing different kinds of cracks, the proposed technique has been tested successfully and positively, and its performance is better than several existing crack detection algorithms (Zou et al., 2012). This process is shown in Figure 2.8 .

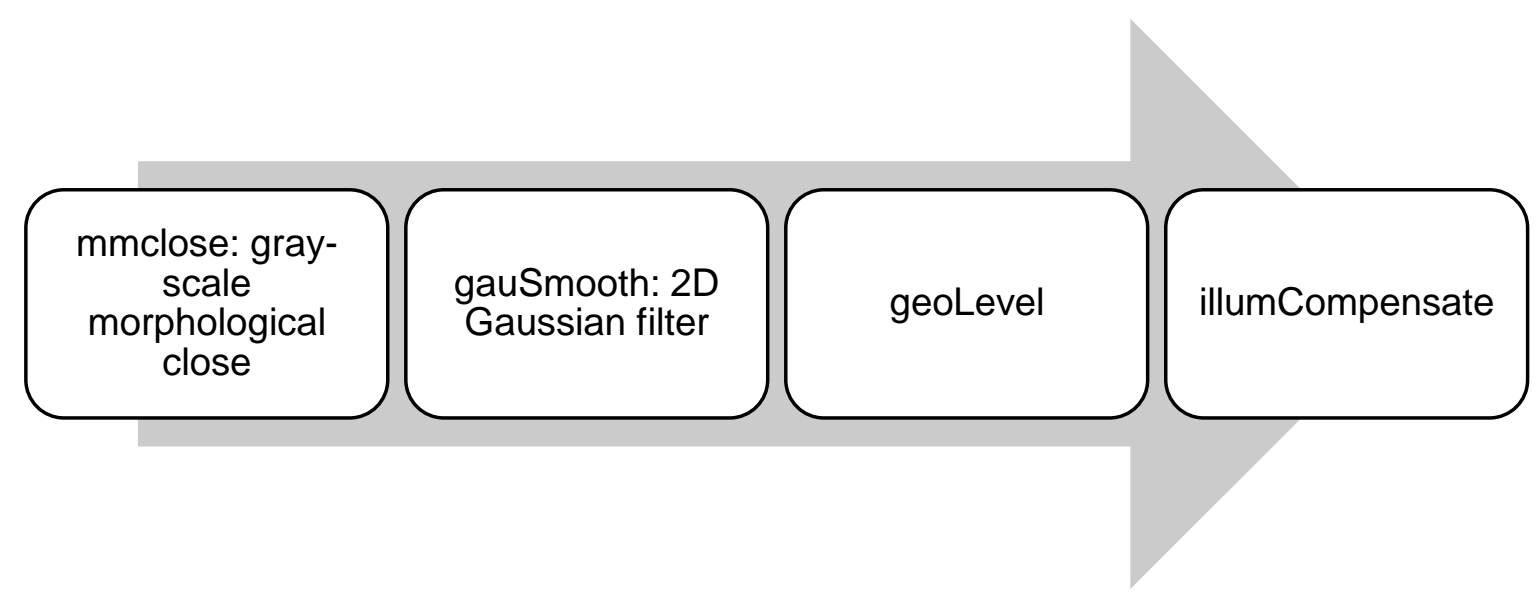

Figure 2.8: The process of applications of algorithms for shadow removal in Zou et al.'s (2012) research

With the development of automatic crack detection techniques for asphalt pavement images, another innovative algorithm has been developed by Amhaz (2016) based on minimal path selection. This technique includes both the photometric and geometric characteristics of images during the image processing stage by localisation of minimal paths and application of two post-processing steps as shown in Figure 2.9. In this study, the existing minimal path selection is improved by this algorithm to estimate the thickness of crack patterns with an additional artefact filtering step. In comparison to five alternative techniques for crack detection on asphalt pavements, the proposed technique can afford the best Dice Similarity Coefficient (DSC) rate. The results show this method has generated precise and robust cracking detection results in various situations and in a fully unsupervised manner (Amhaz et al., 2016). 

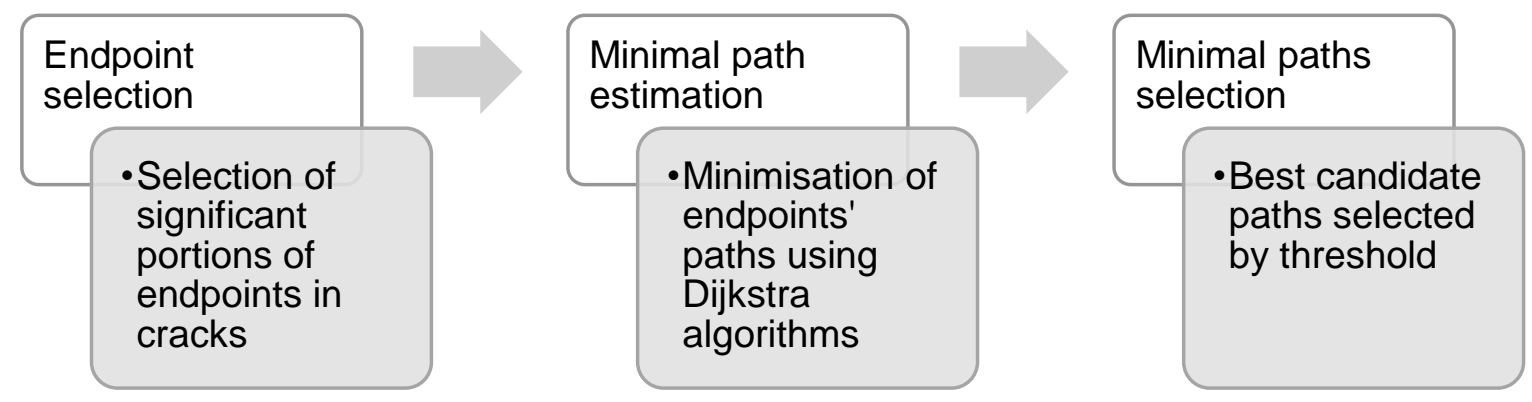

Figure 2.9: Core steps of the minimal path selection technique in Amhaz et al.'s (2016) study

According to the abovementioned ML-based techniques for crack classification and detection on concrete surface, the same concept can be applied to the crack detection on asphalt pavements. In view of the challenges of intensity inhomogeneity of cracks, complex backgrounds, and low contrast with surrounding pavement and shadows, Zhang (2016) developed a deep learning-based method for crack detection on pavements through the successful application of deep learning in CV. Another key step was to train a supervised deep CNN to classify each patch of acquisition images. Based on 500 sample images, the experiment successfully shows the proposed deep learning technique can generate high crack detection performance for pavement images (Zhang et al., 2016b). The core steps of the automatic pavement cracking detection used by Zhang et al., is shown in Figure 2.10.

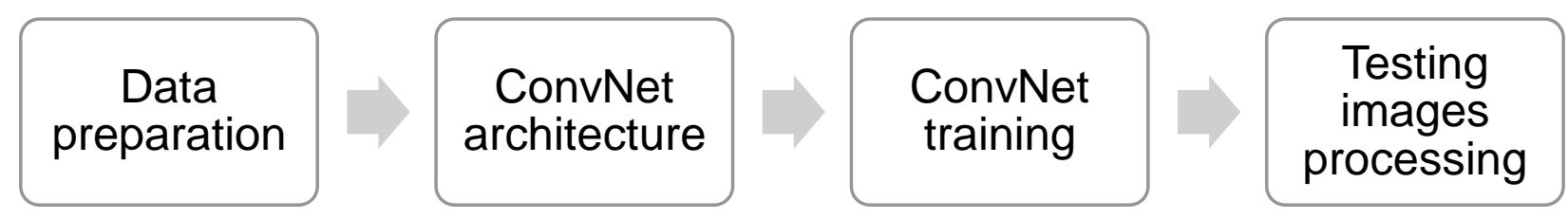

Figure 2.10: Core steps of the automatic pavement cracking detection using deep learning-based technique in Zhang et al.'s (2016) study

Based on the abovementioned existing techniques for automatic detection of external defects from both concrete and pavement images, the level of performance can be concluded in Table 2.1. The level of performance in the table indicates identification of only the defect and the characteristics of the defect such as length and width for each transport structure. The overall process of automatic structural inspection and data processing discussed in foregoing sections is summarised in Figure 2.11. 
Table 2.1: Summary of level of automatic external defect detection at current stage

\begin{tabular}{|c|c|c|c|}
\hline $\begin{array}{l}\text { Transport } \\
\text { infrastructure }\end{array}$ & $\begin{array}{l}\text { External defect } \\
\text { types }\end{array}$ & $\begin{array}{l}\text { External defect } \\
\text { detection }\end{array}$ & $\begin{array}{l}\text { External defect } \\
\text { recognition } \\
\text { (width and length) }\end{array}$ \\
\hline \multirow{3}{*}{$\begin{array}{l}\text { Reinforced } \\
\text { concrete bridge }\end{array}$} & Cracks & \multirow[t]{3}{*}{ Achieved } & Partially achieved \\
\hline & Spalling & & Partially achieved \\
\hline & Honey combine & & Partially achieved \\
\hline \multirow{2}{*}{$\begin{array}{l}\text { Precast concrete } \\
\text { tunnel }\end{array}$} & Cracks & \multirow[t]{2}{*}{ Achieved } & Partially achieved \\
\hline & Spalling & & Partially achieved \\
\hline \multirow[t]{3}{*}{ Asphalt pavement } & Cracks & \multirow[t]{3}{*}{ Achieved } & Achieved \\
\hline & Potholes & & Partially achieved \\
\hline & Patches & & Partially achieved \\
\hline
\end{tabular}




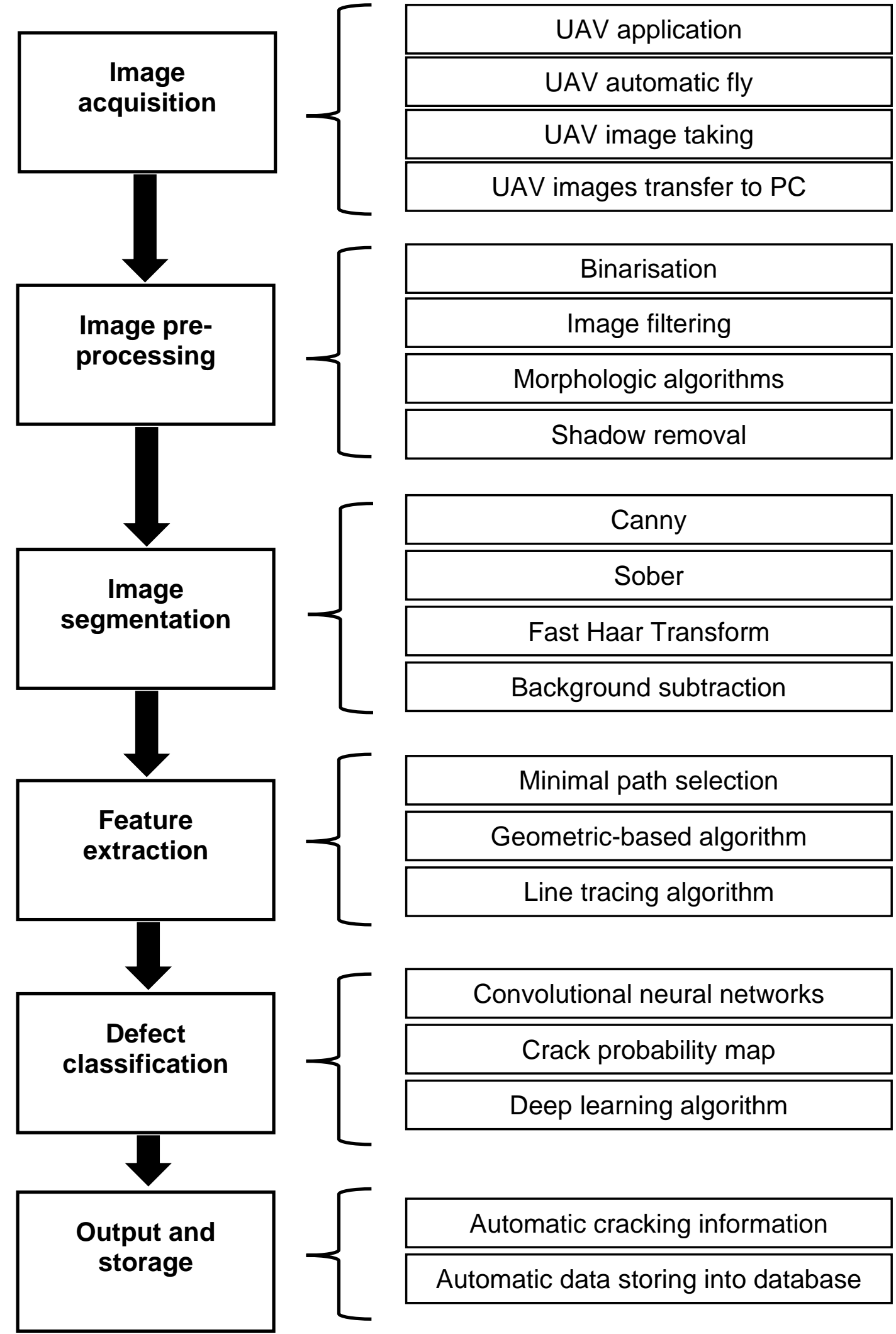

Figure 2.11: Overall process of automatic structural inspection and data processing 


\section{Automation in data processing for internal defects}

Non-Destructive Testing (NDT) is one of the most commonly used methods in the field of deteriorating civil infrastructure (Maizuar et al., 2020, Maizuar et al., 2018, Maizuar et al., 2017a, Kafle et al., 2017a, Zhang et al., 2016a). It has been widely used to identify individual defects without causing any harm to the remaining tested structure. Some of the methods may also detect localised damage to the concrete surface, known as "partially-destructive". However, there is no single NDT to date that can provide complete information since each method has its limitations. Accordingly, there is often a need to choose more than one technique to get a complete picture of damage within a structure.

Given the limitations of NDT in obtaining a holistic picture of deterioration, it is important to choose the appropriate one by undertaking a prior study to assess the relevance of a technique for a particular health assessment need. Several NDTs have been appraised and are available in literature as well as in the commercial market. Some of them are being used broadly by bridge monitoring agencies while some are highly specialised, including ground penetrating radar (GPR), infrared thermography (IRT), impact echo (IE), ultrasound pulse velocity (UPV), ultrasonic surface waves (USW), MIRA, interferometric radar system (IBIS-S), three dimensional optical measurement system (ARAMIS) acoustic emission (AE) and CV-based crack detection (Rehman et al., 2016, Koch et al., 2015a). McCann and Forde (McCann and Forde, 2001) have described five major factors that need to be considered before deciding on the NDT survey. These factors are (1) required depth of structure to be investigated, (2) resolution of the target, (3) contrast in physical properties between surroundings and target, (4) signal to noise ratio for the physical properties, and (5) design and construction information of the target. A 3D optical measurement system available at the University of Melbourne is shown in Figure 3.1 and the schematic diagram of the application of IBIS-S and ARAMIS in bridge structural health monitoring is shown in Figure 3.2. 


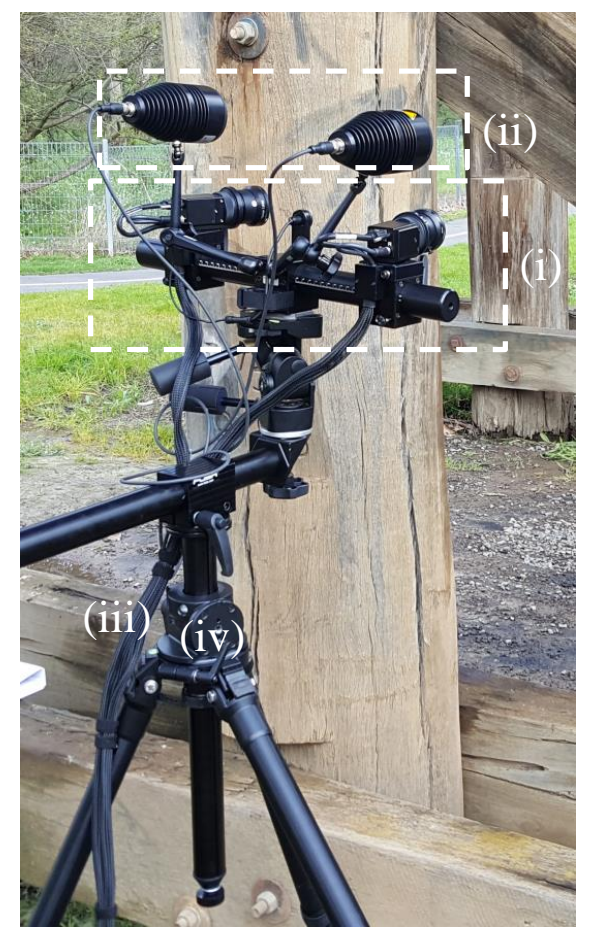

Figure 3.1: Detail of 3D optical measurement system components: (i) right and left cameras; (ii) camera lights; (iii) cable connecting the cameras to data acquisition box; and (iv) tripod

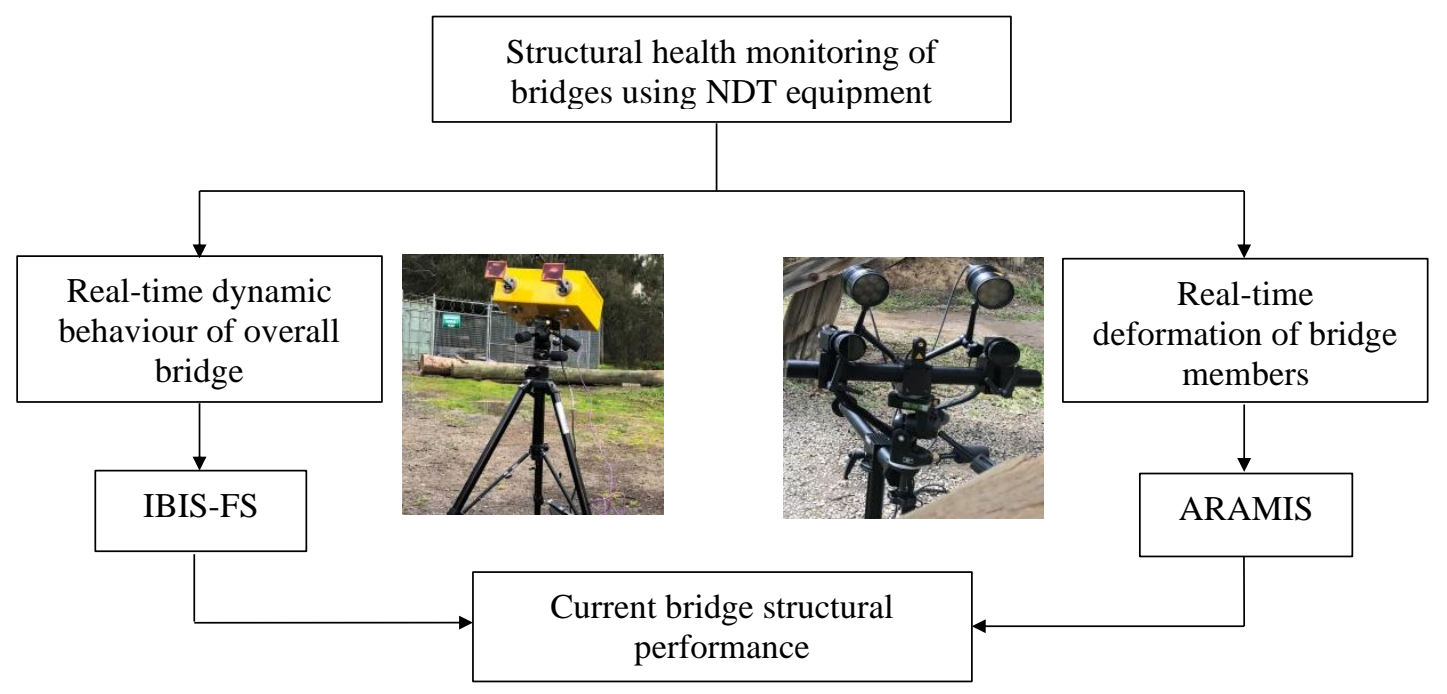

Figure 3.2: Schematic diagram showing the application of IBIS-S and ARAMIS in bridge structural health monitoring 


\subsection{Infrared thermography (IRT)}

Infrared thermography is one of the advanced methods for non-destructive evaluation of reinforced concrete bridges. Infrared thermography is an efficient and effective way for rapid and safe evaluation of bridge components, including substructures, soffit areas, and superstructures (Washer et al., 2009). Traditionally, subsurface defects are monitored by using chain drag and hammer sounding tests as part of a visual inspection of bridges (Hiasa et al., 2017). These tests are based on the principle that the sound from dragging the chain or hitting the hammer on the deck changes from ringing (sound deck) to the somewhat dull and hollow (delamination) (Gucunski and Council, 2013). These techniques require trained inspectors and are time-consuming. Moreover, the accuracy of results is subjective to inspectors' experience and to the surrounding noise. It may further require partial or full road closure for traffic and can potentially put the inspector at risk.

Infrared thermography has the advantage over traditional methods as the inspector can rapidly scan the whole bridge remotely and is able to identify the potential subsurface deterioration by just examining the thermographs obtained by the IR cameras. The technology is able to identify likely delaminated, spalled, and inner void areas from a distance up to $60 \mathrm{~m}$ with reasonable accuracy; thereby avoiding the need for any road closure or suspension of traffic operations. One can also perform it at a normal car driving speed. It can also be combined with other CV-based nondestructive techniques like digital photography and the line scanning camera system to completely automate the bridge inspection procedure and replace the visual inspection so as to increase qualitative data and reduce subjective data.

Infrared thermography uses the temperature gradient between the defected and sound surface $(\Delta T=T d-T s)$ to identify the defect regions in a concrete deck. All objects with temperature above absolute zero $\left(-273^{\circ} \mathrm{C}\right)$ emit IR radiation. The IR cameras are able to detect the emitted radiation from the surface of the object and convert the obtained information in image form. The amount of radiated energy is given by StefanBoltzmann law, i.e. the energy radiated by an ideal black body is proportional to the temperature raised to the power four:

$E=\sigma T^{4}$

where $E$ is the total amount of energy radiated from the surface $\left(W / \mathrm{m}^{2}\right), \sigma$ is the StefanBoltzmann constant $\left(5.6697 \times 10^{-8} \mathrm{Wm}^{-2} \mathrm{~K}^{-4}\right)$, and $\mathrm{T}$ is the temperature of the radiating body. However, the materials in bridge decks never act as ideal black bodies and they do not emit back all the absorbed radiation. The correlation between the true kinetic energy and the emitted energy by radiation is defined by the emissivity of the material and its value lies between 0 and 1. For ideal black bodies, the value of emissivity is equal to one. For concrete, the emissivity value is normally greater than 0.92 (Chen and Chen, 2016). However, it depends upon the surface colour and texture as well as the moisture content on the concrete surface.

There are two approaches to conduct the IRT: active thermography and passive thermography. Active thermography uses the external heat source to stimulate the object, whereas passive thermographic techniques use the heat from the sun and 
ambient environment for stimulation of the object under inspection (Robert, 1982). Passive thermography is the commonly adopted technique for the inspection of civil infrastructure because of their large exposed area for inspection. It is uneconomical and sometimes impossible to use active thermographic techniques to thermally stimulate the whole area that is to be inspected.

The concept behind the passive thermography for delamination detection is that the daytime solar irradiations heat up the concrete surface and heat flows within the concrete by conduction. The delamination or air-filled voids act as a thermal barrier due to its negligible thermal conductivity as compared to concrete. Therefore, the volume of concrete above the delamination heats up quickly and appears as a hot spot during daytime (when heat is travelling into the system from the surroundings). In contrast, during the cooling phase (i.e., no solar irradiation during the night), the thin delaminated region radiates energy quickly to the surroundings and the surface above the defect appears as a cold spot (Holst, 2000).

\subsection{Infrared thermography for bridge subsurface defects inspection}

Infrared thermography has been used for bridge deck delaminations for many years. The first standard test method for IRT for bridge deck was established by ASTM in 1988. The ASTM D4788 describes the desired atmospheric conditions and time of the day along with the procedure to carry out the IR thermographic inspection for bridges. Thermographic inspection has several advantages over other techniques. This technique can furnish the required information for bridge elements without needing access to the specific element. For example, the soffit of a bridge can be imaged from the ground and the deck of bridge can be observed by standing on the sides of the bridge. Based on the data collection procedure, the current practice for IRT can be divided into three categories:

1. Handheld or manually operated IRT;

2. Motorised vehicle-mounted IRT;

3. UAV IRT.

In handheld thermography, the IR camera is usually manually operated by an inspector. With vehicle-mounted IRT, the bridge surfaces (usually decks) are quickly scanned at normal driving speed $(50-60 \mathrm{~km} / \mathrm{h})$. A UAV IRT has an IR camera mounted on a UAV either remotely or controlled by a navigator on the ground. It contains inflight data acquisition and post-flight image processing and can fly autonomously by defining a pre-programmed flight path before inspection or semi-autonomously as a combination of both.

The vehicle-mounted and UAV IRT, have become important tools for automation in bridge subsurface defect detection. Vehicle-mounted IRT is used for a quick scan of bridge decks, whereas the UAV-based thermography has the advantage of remotely accessing any area of a bridge structure. For vehicle-mounted IRT, the speed of the vehicle influences the thermal photographs and for UAV-mounted thermography, the stability and flying speed of drones also affect the thermal results. 


\subsection{Thermal image processing/data interpretation}

Infrared imagery technology produces best results when the thermal contrast is detectable over time. The structure itself has different temperatures depending upon location and orientation of the structure with respect to the sun. Therefore, it is not always possible to detect subsurface anomalies of concrete from the colour variation of thermal images. Akashi et al. (Akashi et al., 2006) developed a relationship between temperature variation and inherent damage characteristic of concrete from analytical and statistical studies. They developed a damage classification system that automatically classifies the damage rate into three categories: "Critical" (crack exists on concrete surface and immediate attention is required), "Caution" (crack exists within $2 \mathrm{~cm}$ from the concrete surface and close monitoring is recommended) and "Indication" (currently satisfactory). The raw IR data is filtered and processed using image processing techniques via the software and classified as shown in Figure 3.3.

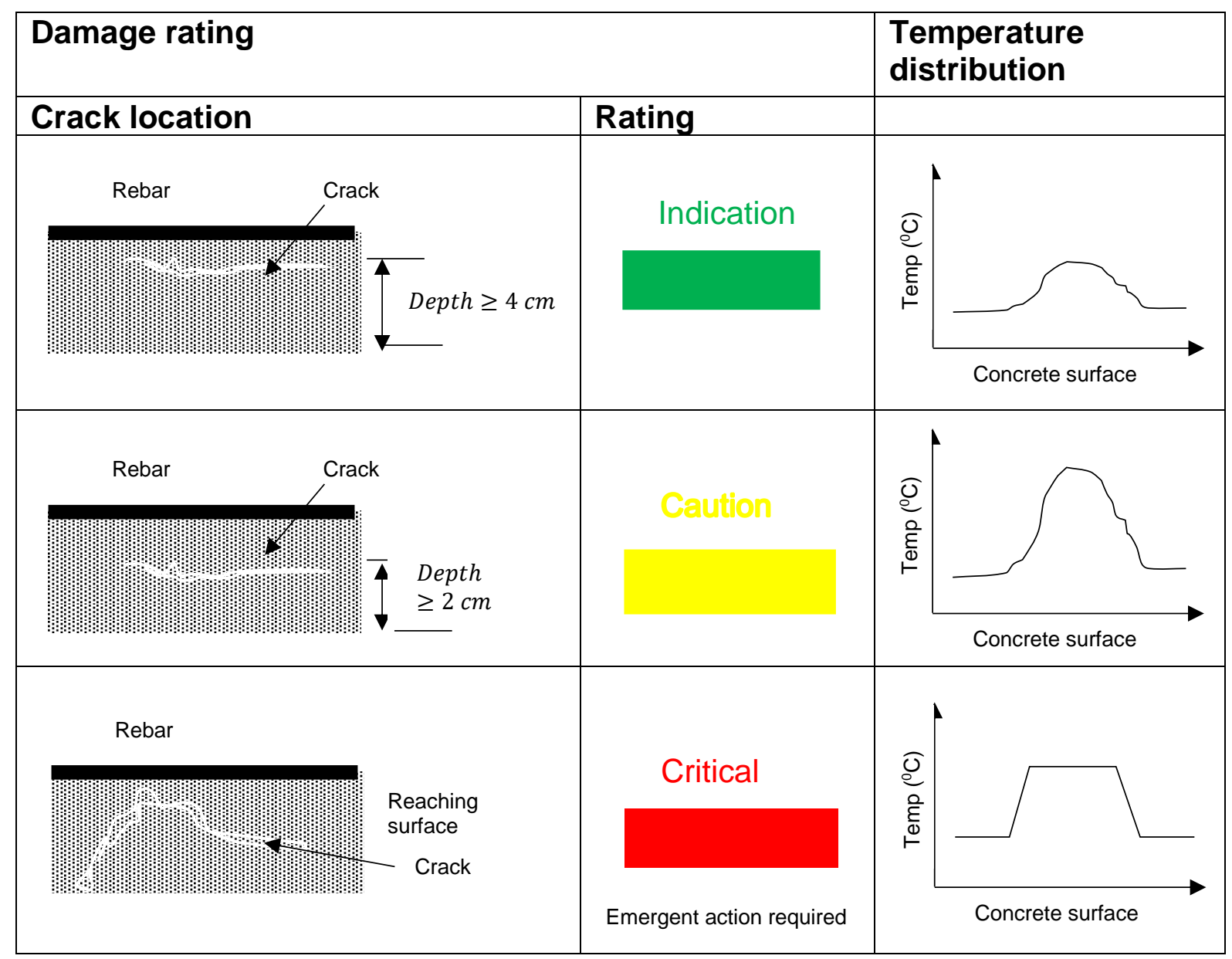

Figure 3.3: Subsurface damage rating by infrared thermography (Akashi et al., 2006)

Advancing the UAV-based SHM research, (Omar et al., 2018) used UAVs equipped with IR cameras to automate the subsurface damage detection of concrete bridge 
decks. The images taken by UAV-mounted thermal camera were stitched together by using algorithms to form a mosaic of the bridge deck. K-mean clustering technique was used to form different thermal clusters and categorise the defects into severity groups.

The University of Melbourne SHM group engaged in conducting studies using IR cameras, integrated with a remotely piloted aircraft, to inspect roads in Melbourne. Figure 3.4 indicates the surface damage captured on one of the roads and the damage identified by infrared thermography is shown in Figure 3.5.

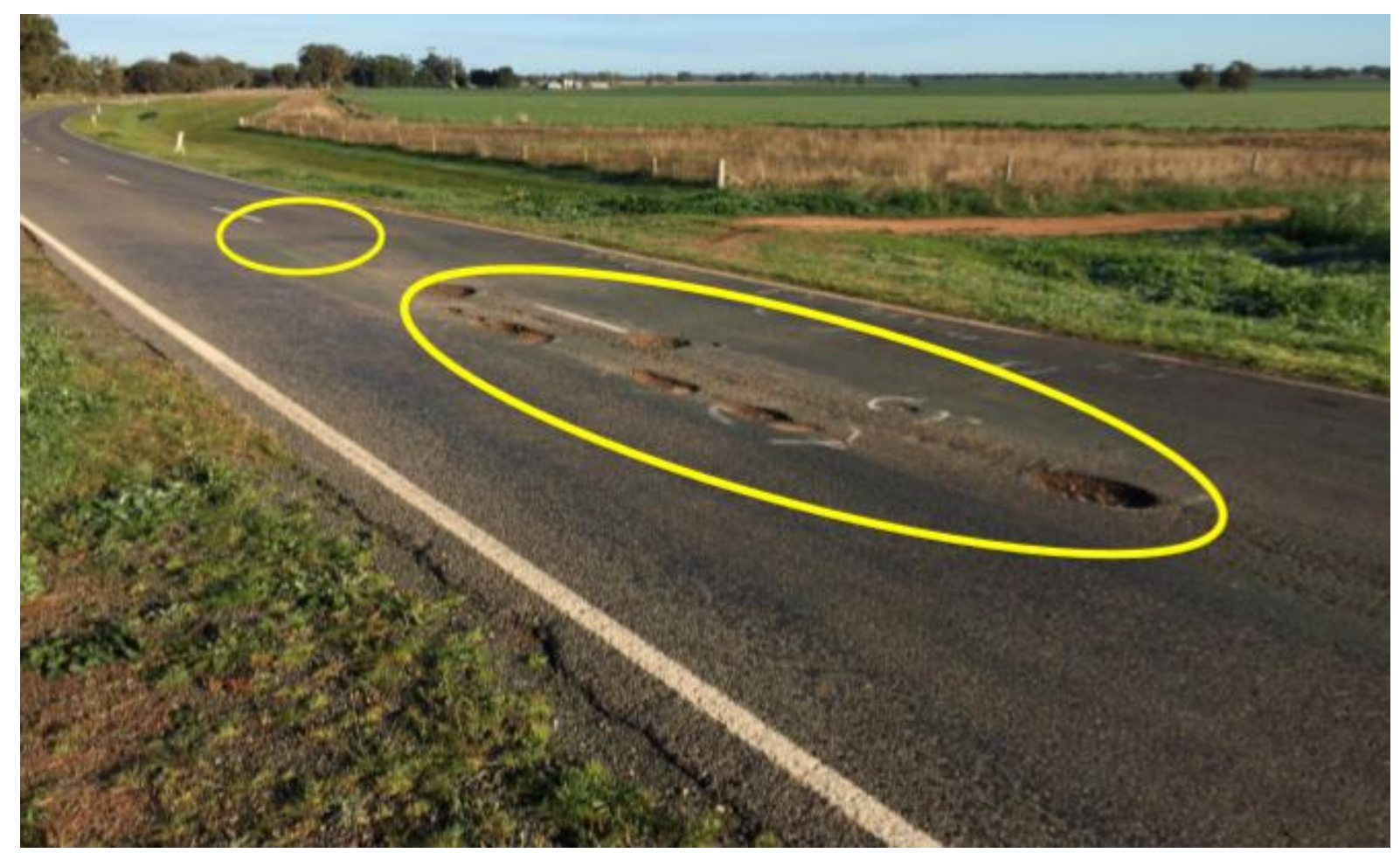

Figure 3.4: Subsurface damage of a road 


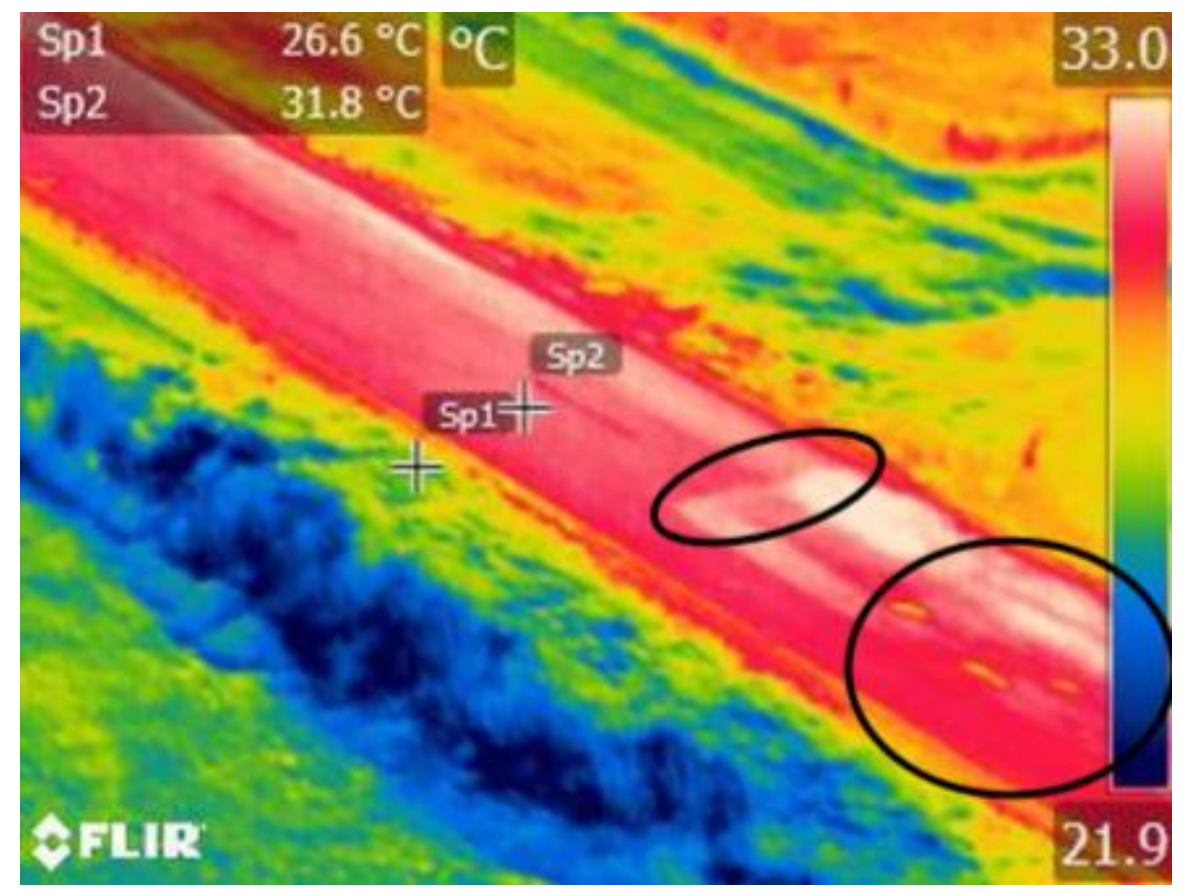

Figure 3.5: Subsurface damage indicated by infrared thermography

It is always a challenge for bridge inspectors to detect the surface and internal defects and analyse these defects in road infrastructure. The application of different automated data acquisition and data processing techniques discussed in the foregoing sections enhances the process in SHM.

\section{Automation in life-cycle performance assessments}

Performance assessment and monitoring of road infrastructure is an important aspect in effective maintenance in many countries. A deterioration model is the key element in a BMS to predict the future performance of the infrastructure system. There are different methods available in predicting deterioration models in an automatic manner. In this section, the reliability-based analysis method, general algorithms (GAs) and artificial intelligence $(\mathrm{Al})$ are discussed in detail.

\subsection{Reliability analysis}

Reliability-based performance assessment methods are one of the most accepted methods used in estimating life-cycle performance of transport infrastructure. This method accounts for both aleatory and epistemic uncertainties. Reliability theory relates to determining the probabilistic measure of a safe performance.

Estimating the service life of any structure requires a model capable of predicting the structure's performance over time; which depends on both external (e.g., environmental demands) and internal aspects (e.g., material degradation) and their relationship with the structural performance. Predicting the residual life of a bridge is 
challenging and involves the estimation of progressive damage accumulation due to bridge ageing (e.g., corrosion and degradation of bridge materials) and immediate damage caused by impacts such as truck impact or earthquake (Ausroads 2004; Urs et al. 2015).

The residual life of a deteriorating structure subject to this combined effect of different deteriorating mechanisms is usually obtained from the so-called life-cycle performance model. The life-cycle performance of a structure throughout its lifetime is generally affected by time-variant deterioration effects of continuous degradation and damage processes due to sudden extreme events (e.g., earthquake, truck impact, etc.) (Estes and Frangopol, 2005, Stein et al., 1999, Guo and Chen, 2015, Frangopol and Soliman, 2016). Further, the structural lifetime performance depends on how these mechanisms interact; those deterioration mechanisms, their effects and evolution over time are generally complex (Biondini and Frangopol, 2016). Different types of deterioration mechanisms, their interactions and the consequences on the structural performance can be found in papers by (Sánchez-Silva et al., 2016, Sanchez-Silva et al., 2011).

Studies on structural deterioration can be grouped into two broad categories: progressive and shock based. While progressive degradation (e.g., corrosion) is a timedependent phenomenon that continuously depleted at a rate over structural lifetime, shock degradation (e.g., truck impact) describes sudden changes in the structural performance over small-time intervals. Both mechanisms cause damage accumulation over time (Sanchez-Silva et al., 2011, Sánchez-Silva and Klutke, 2016, Junca and Sanchez-Silva, 2013, Riascos-Ochoa et al., 2014, Maizuar et al., 2017b, lervolino et al., 2013, Kafle et al., 2017b, Lua et al., 2014). Previous studies on progressive deterioration of reinforced concrete structures have focused on chloride ingress that results in steel reinforcement corrosion, concrete creep, cracking and loss of bond, and spalling ((Melchers et al., 2008, Ellingwood and Mori, 1993, Lihai et al., 2013, Koh et al., 1997b, Sofi et al., 2011, Baidya et al., 2013). Most shock-based degradation and failure models are associated with earthquakes (Rackwitz et al., 2005, Sánchez-Silva and Rackwitz, 2004). The effect of both earthquake damage and progressive deterioration has been investigated (Sanchez-Silva et al., 2011, Yang and Klutke, 2000).

Consider a structural system with an initial capacity $u_{0}$ (Figure 4.2). As deterioration increases, the capacity of the component decreases. If $D(t)$ describes the accumulated deterioration of the component at time $t$; the remaining life of the component at time $t$ can be expressed as:

$$
V(t)=u_{0}-D(t)
$$

An intervention (maintenance or reconstruction) is carried out once the remaining life of the system reaches a threshold value. In Figure 4.1, a single threshold value, i.e., $S^{*}$, (limit state) is considered. In this case, it represents the minimum level of performance of the system (i.e., a level below which the system cannot be in service under any circumstance; note that this does not necessarily imply collapse). Other threshold values can be defined if necessary; for example, operational or safety 
thresholds. In summary, the system will be in acceptable operation as long as the capacity is larger than a given value $s^{*}$ in Figure 4.1; and the system will be out of service once the capacity falls below $s^{*}$ and until it is repaired and taken to a new "initial" remaining life value $u>s^{*}$. Finally, after the intervention, the condition of the structure will reach a new value corresponding to a capacity that might differ from the value at the beginning of the previous cycle.

Consider a structural component with a sample path as the one shown in Figure 4.1. Assuming that both continuous and sudden damaging events are independent, the deterioration at time $t$, for the first cycle can be computed as:

$D(t)=\int_{0}^{t} r_{p}(\tau) d \tau+\sum_{i=1}^{N_{t}} Y_{i}^{S}$

where $r_{p}$ is the rate of some continuous progressive deterioration processes (e.g., corrosion), $N(t)$ is a random variable that describes the number of shocks at time $t$, and $Y_{i}^{S}$ is the drop in structural capacity caused by the $i$-th shock. The remaining capacity of the structure is obtained by combining Equations (2) and (3) to give

$$
V(t)=u_{0}-\left(\int_{0}^{t} r_{p}(\tau) d \tau+\sum_{i=1}^{N_{t}} Y_{i}^{s}\right)
$$

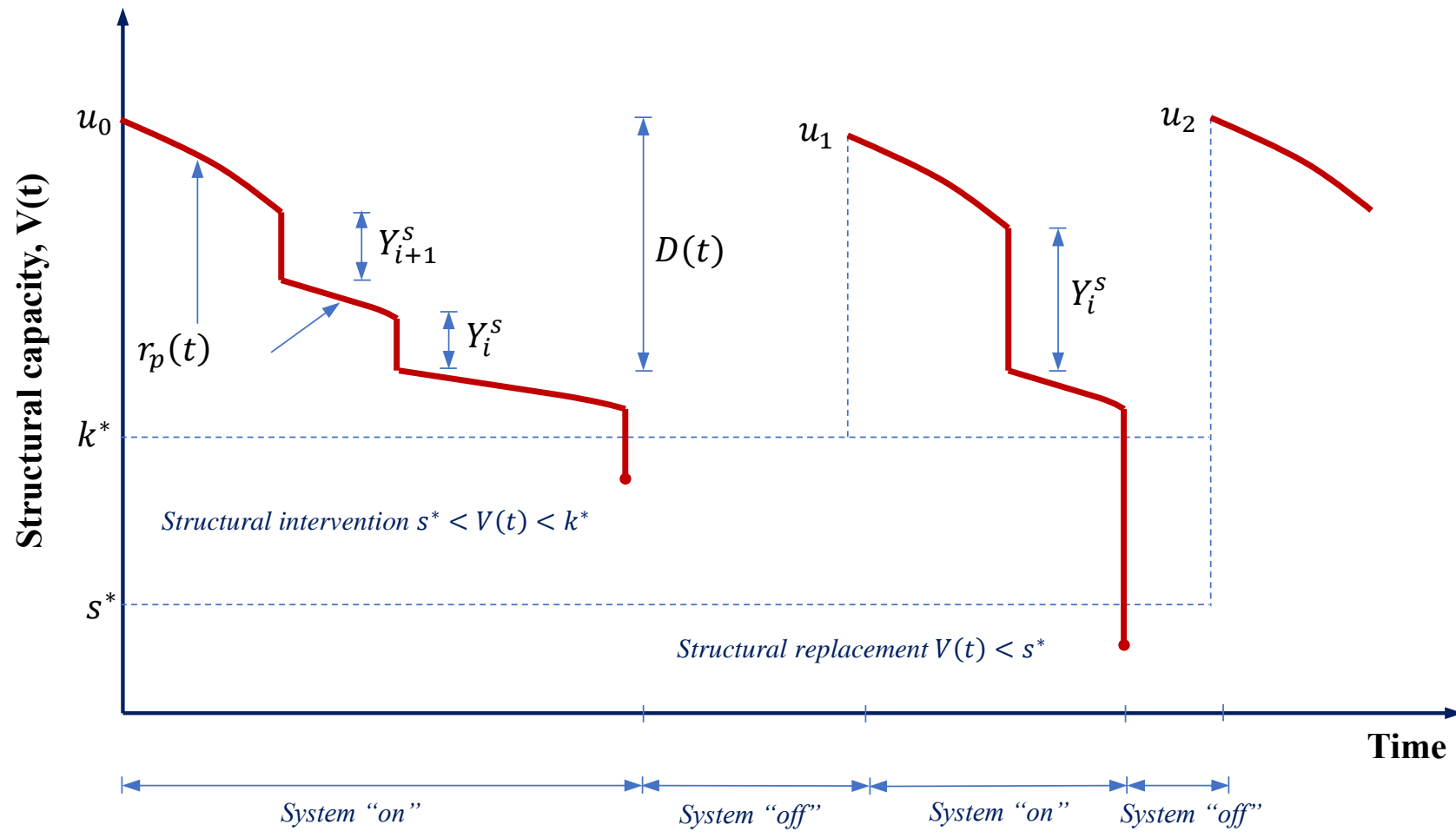

Figure 4.1: Life-cycle performance of a structure throughout its lifetime (SanchezSilva et al., 2011) 


\subsubsection{Case study}

The abovementioned approach for predicting residual life of bridges subjected to multiple truck impacts was implemented for the case of a bridge in South Melbourne, Australia (i.e., Montague Street Bridge shown in Figure 4.2). This railway bridge is highly vulnerable to truck impacts due to its relatively low clearance heights (Preston, 2017). This steel box girder bridge is $70 \mathrm{~m}$ long and has a width of $7.5 \mathrm{~m}$. The railway overpass bridge is used to serve Melbourne's metropolitan electric railway network in order to reduce congestion with traffic road under the bridge.

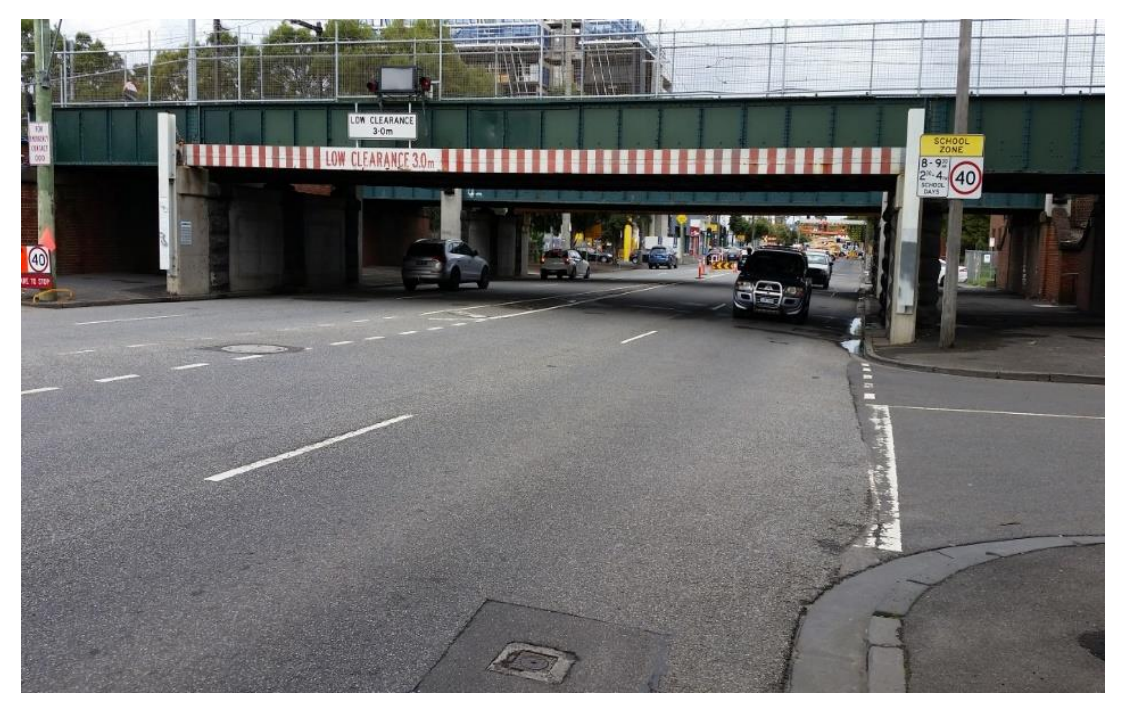

Figure 4.2: Montague Street Bridge in South Melbourne, Australia

Figure 4.3 shows the probability of failure of the bridges as a function of time as a result of progressive deterioration only, multiple truck impacts only and the combination of both progressive deterioration and multiple truck impacts, respectively. Figure 4.4 shows random sample paths describing probability of failure of a bridge under progressive deterioration. Under normal progressive deterioration only, the average and shortest expected bridge lifetimes are around 65 years and 100 years, respectively. Under multiple trucks impacts only, the results in Figure 4.5 indicate the average residual life of the bridge could significantly be reduced to 57 years. Further, when the combined effect of progressive deterioration and multiple truck impacts are considered, the average residual life could be reduced by $65 \%$. The results indicate the impact of progressive deterioration and multiple truck impacts on bridge lifetime should be investigated in an integrated manner. 


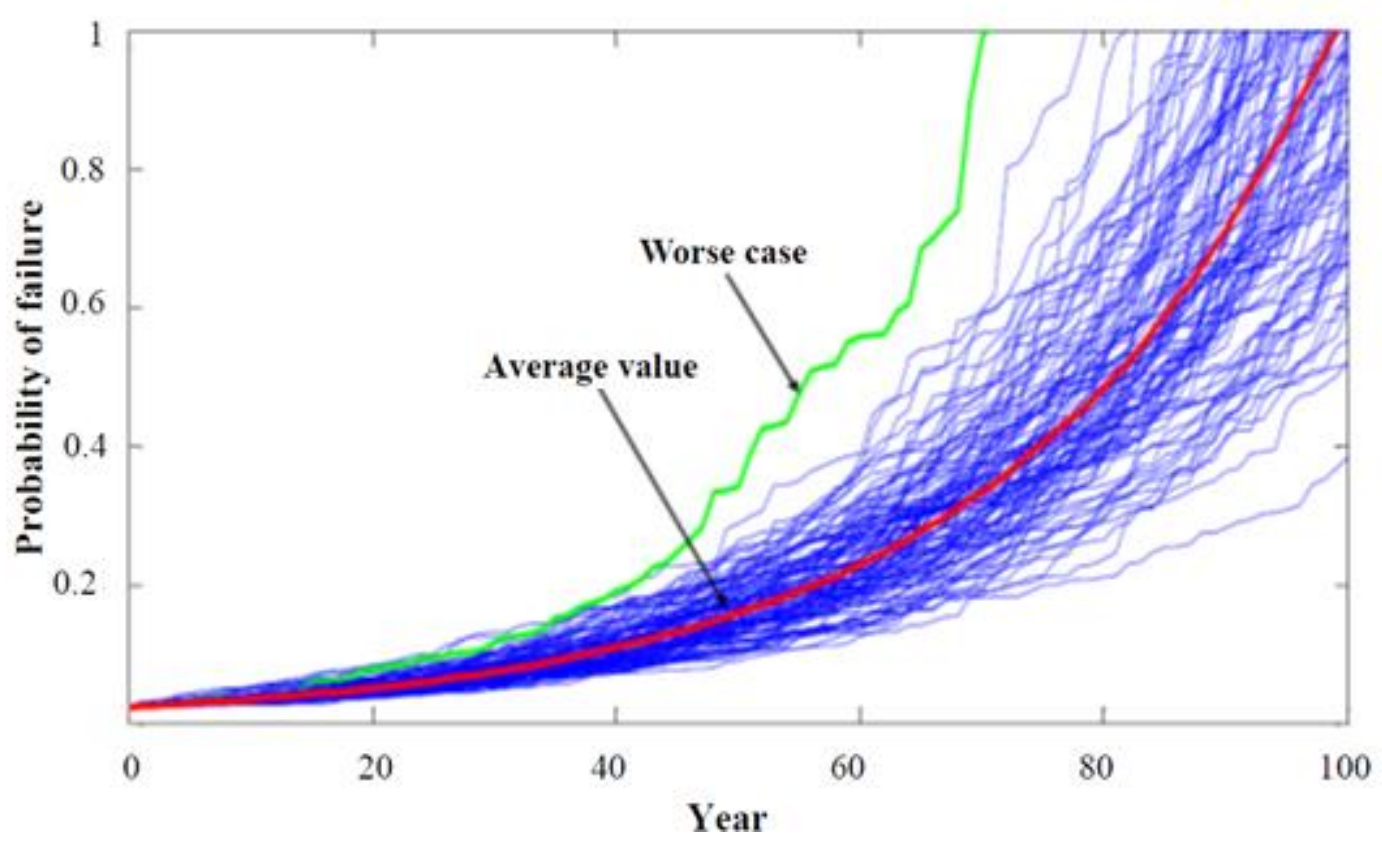

Figure 4.3: Time-dependent probability of failure of the bridge as a result of progressive deterioration only

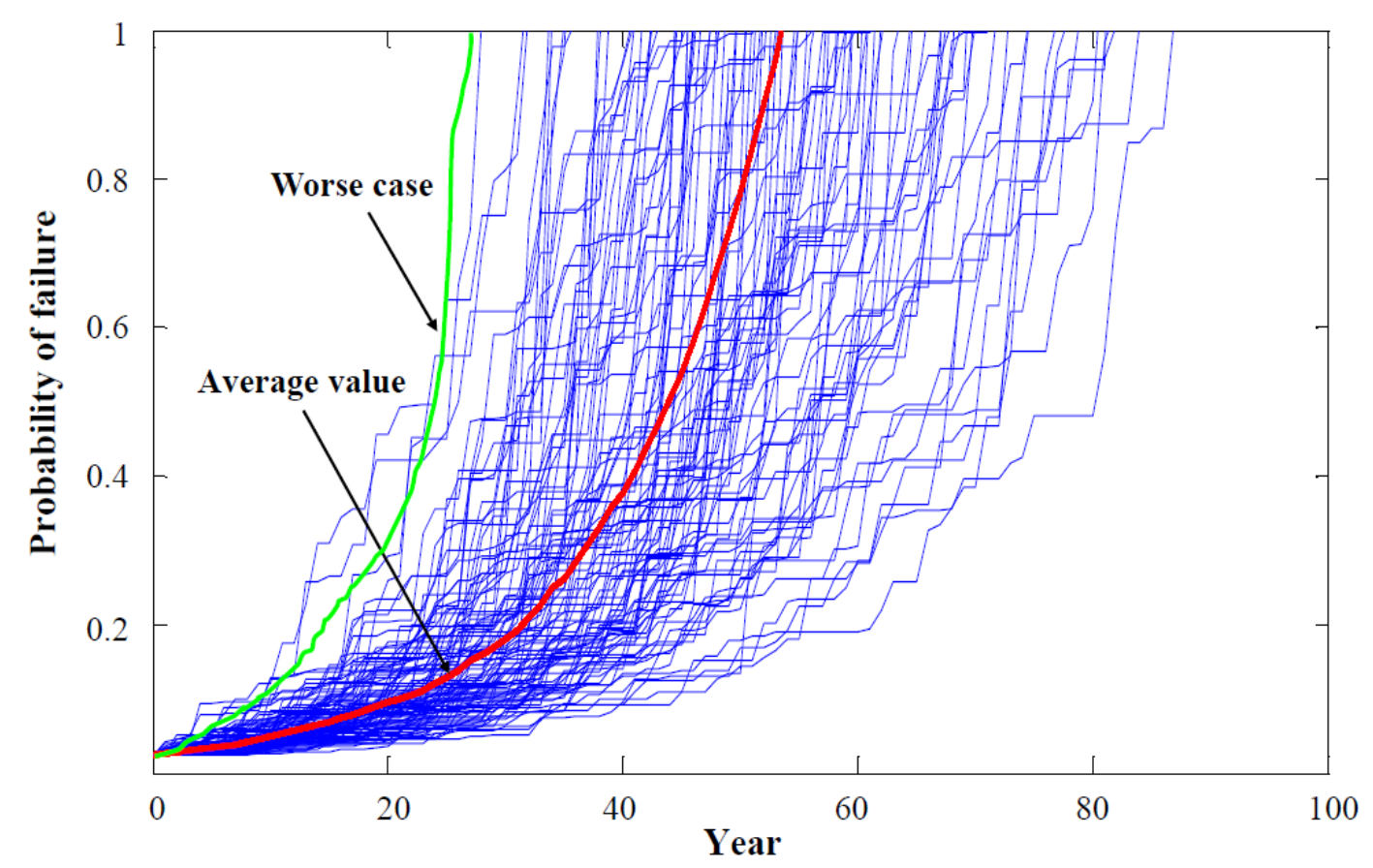

Figure 4.4: Time-dependent probability of failure of the bridge as a result of multiple trucks impacts only 


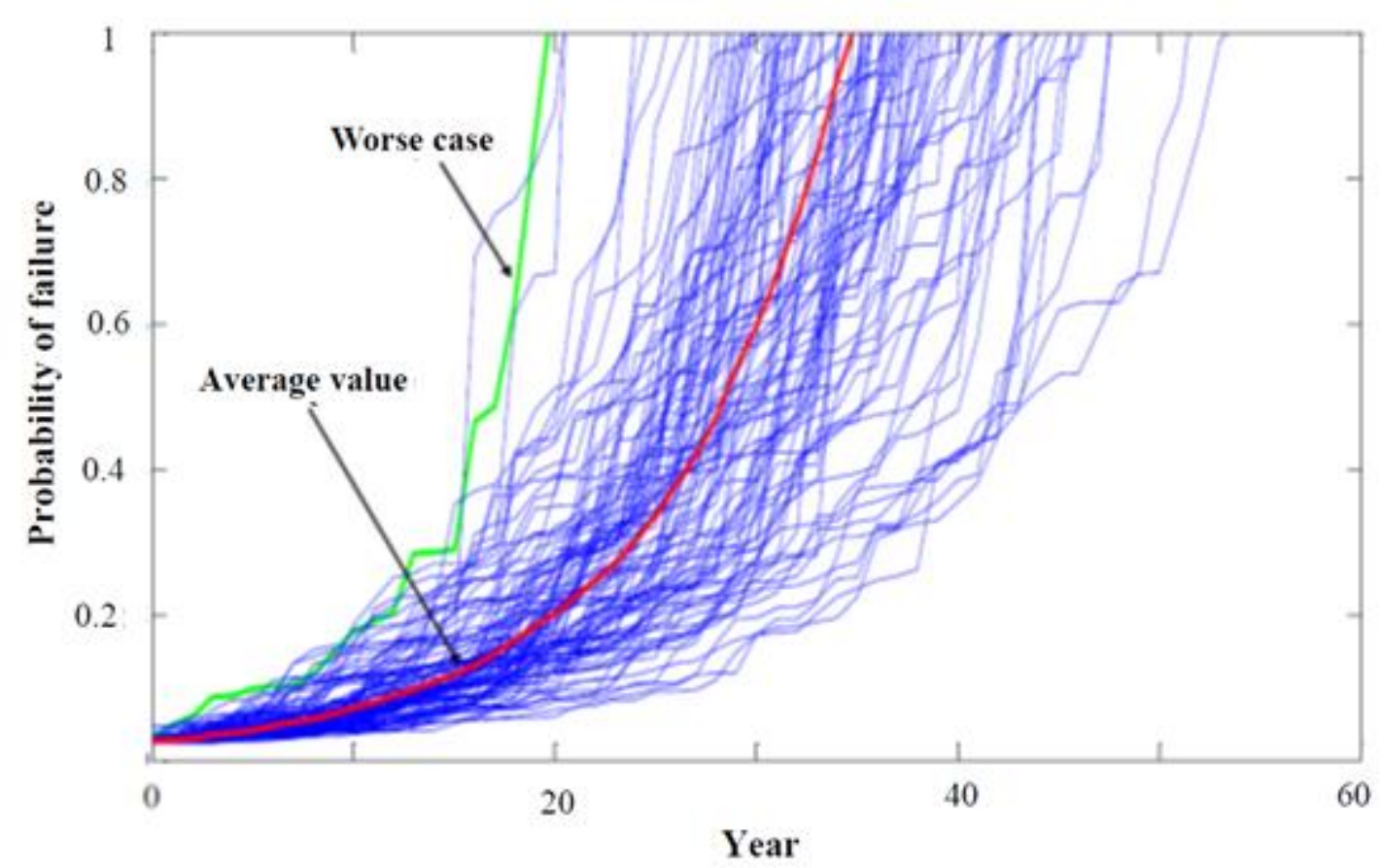

Figure 4.5: Time-dependent probability of failure of the bridge as a result of combination of both progressive deterioration and multiple trucks impacts

\subsection{General algorithms (GAs)}

General algorithms (GAs) were developed by Holland (1972) based on principles of natural selection and genetics, and later this concept was used in many engineering applications such as in transport networks by Xiong and Schneider (1992). Following this, the use of GAs in maintenance optimisation techniques, introduced by Fwa, Tan, and Chan in 1994, was popular in road network applications. PAVNET (Fwa et al., 1994) was developed to investigate the maintenance planning of pavement networks and an updated version was developed to solve the trade-off between maintenance and rehabilitation activities (Fwa, et al. 2000; Fwa, et al. 1996). The bridge deck network is an important aspect in road infrastructure network and GA-based models were developed to identify optimum maintenance strategies for long-term solutions (Liu, et al., 1997; Miyamoto et al., 2000). Many of these models use linear or nonlinear deterministic deterioration models to predict the future condition of road infrastructure. GAs in optimisation techniques are popular due to the efficiency and the increasing likelihood of obtaining results within a reasonable time frame (Goldberg 1989).

The uncertainty due to the nature of infrastructure deterioration is considered through the use of stochastic methods such as Markov chains. These methods can be used to predict performance through discrete time intervals and transition from one interval to the other. Pontis, BRIDGIT, and MicroPAVER are some of the examples of infrastructure systems and components that use Markov chains in predicting the future condition of infrastructure. 
Although Markov chain models are used in many BMSs, there are some limitations:

- Assumption of past conditions have no effect on predicted condition (Madanat,1993).

- Assumption of discrete transition time intervals and stationary transition probabilities which are unrealistic sometimes. This means it does not consider the process development of the bridge in the past and significant repairs that have been made in the past are not considered.

- Deficiency in consideration of interactive effects among the deterioration mechanism of different bridge components, hence different bridge components are computed separately, and overall bridge deterioration prediction is difficult.

\subsection{Artificial Intelligence Deterioration Models}

An artificial neural network is an information processing tool that models biological processes in the nervous system. This concept is transformed to computer-based systems that follow instructions through mathematically formulated algorithms to solve a problem. There are two main stages in Al, namely, training and testing. The model learns on a case-by-case basis and the training process determines the correlation to predict data patterns.

Artificial intelligence techniques such as ANN, case-based reasoning (CBR), and ML, are commonly used to solve engineering problems. Many researchers focus on developing and improving BMSs through improvements in functions and tools. The most effective feature in ANN is that it determines the missing values and patterns in the historical dataset and provides meaningful conclusions.

There are three main types of ANN namely, one-layer feed forward, multi-layer feed forward, and recurrent. A multi-layered neural network is shown in Figure 4.6.

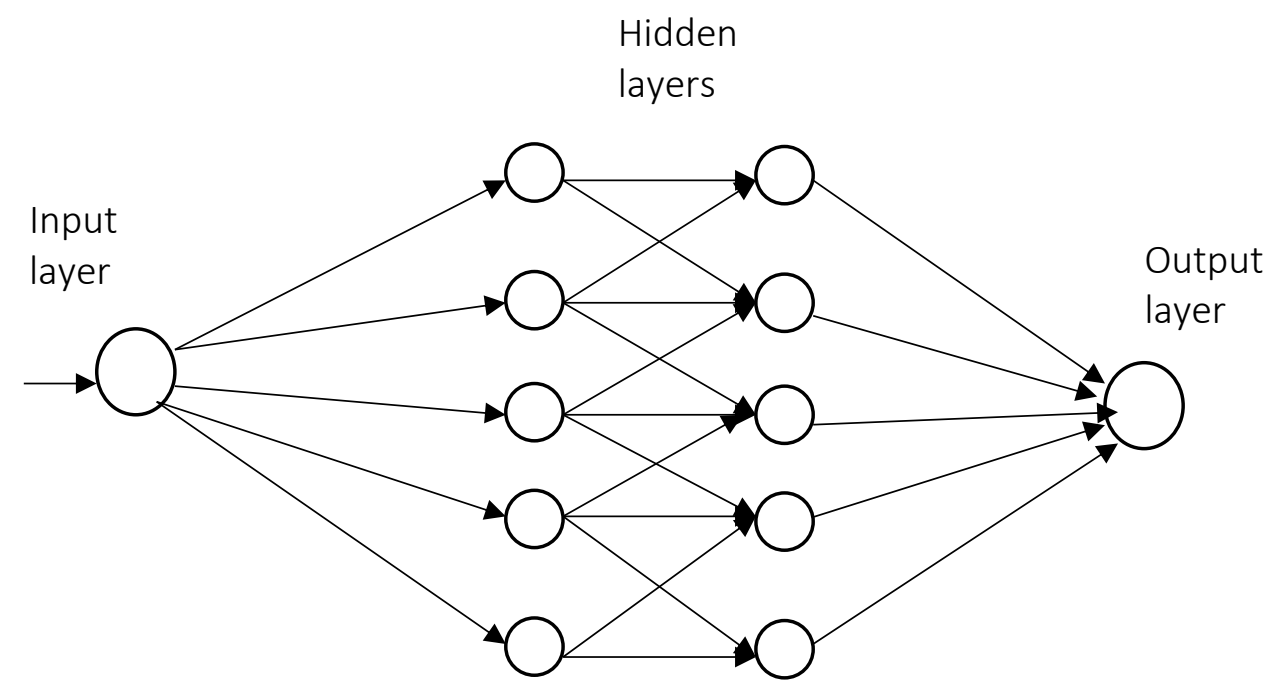

Figure 4.6: Schematics of a Multi-layer neural networks 
In relation to structural condition assessments, neural networks have been used to identify the magnitude of the damage in the structural system. Sobanjo (1997) used the Multi-layer Perception (MLP) Model to predict condition ratings of bridge superstructure by using the age of the bridge. Artificial neural networks are also used to predict ratings of different structural elements (Li \& Burgueño 2010). The lack of historical training data motivated the development of ANN to generate past condition ratings to predict future ratings (Lee et al. 2008).

Ensemble neural networks (ENN) is a combination of many individual MLP models that have been used to determine the output. The schematic diagram of an ENN is shown in Figure 4.7.

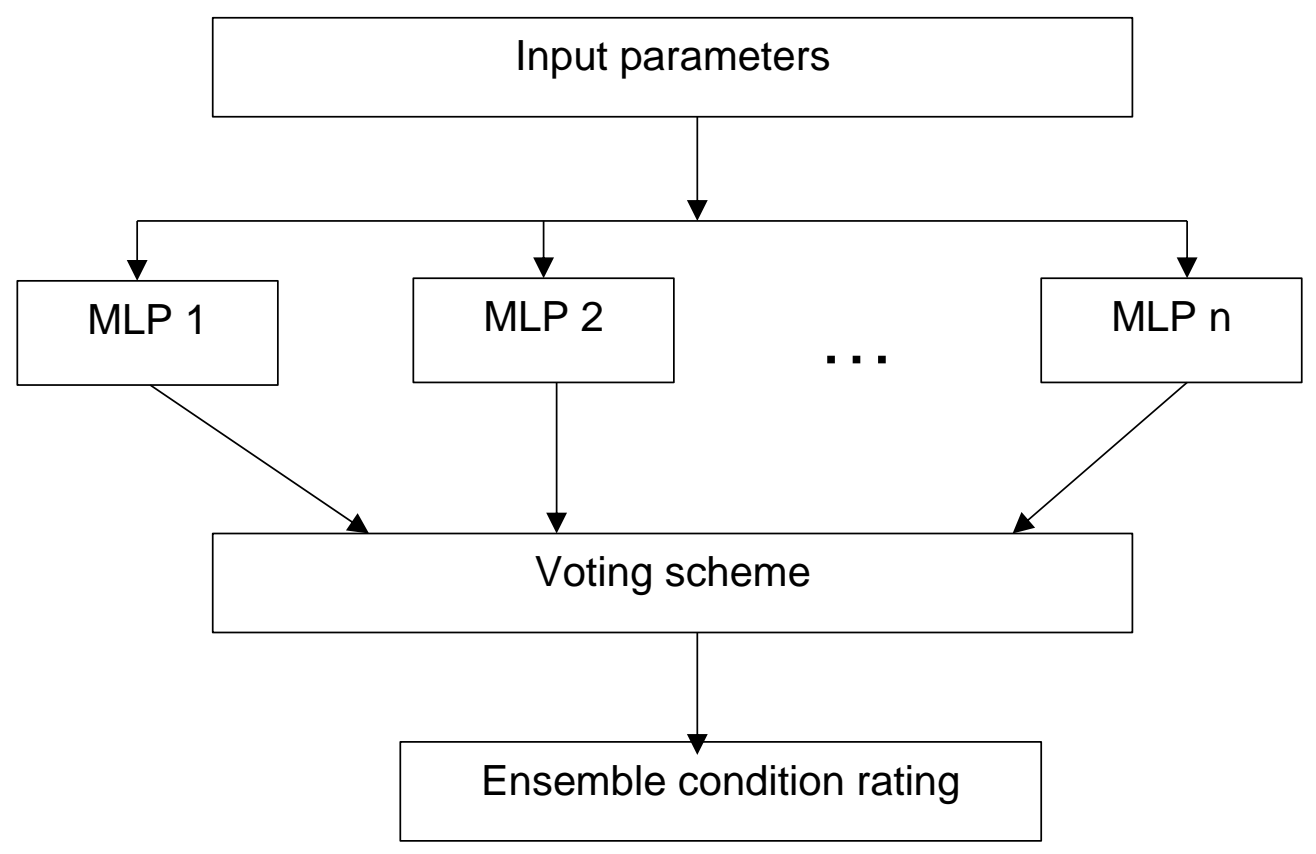

Figure 4.7: Schematic diagram of an ensemble neural network

\section{MLP, multi-layer perception}

There are four main characteristics that distinguish ensemble methods (Rokach \& Maimon 2005):

- Inter-classifier interaction;

- Voting scheme;

- $\quad$ Diversity generator;

- $\quad$ Ensemble size.

The inter-classifier interaction refers to how each individual classifier affects the other classifiers, while the voting scheme is the method used to combine the individual classifier outputs to achieve the ensemble output. The success of the ensemble is dependent on the diversity of individual classifiers and the number of classifiers in the 
ensemble. The classification accuracy can be improved by using diversified classifiers and this occurs due to the development of uncorrelated errors between the classifiers (Hu 2001).

Ensemble neural networks have been used in many applications in bridges such as identifying damage in timber bridges (Dackermann et al. 2009) and predicting bridge abutment condition ratings (Li 2008).

\section{Conclusion}

Road structures require significant maintenance and rehabilitation. However, road authorities currently face numerous challenges in maintaining road infrastructure assets due to inexact and incomplete information arising from an uncertainty of future traffic demand and degradation of construction materials (Zhang et al., 2013, Koh et al., 1997a). Through the implementation of automation in structural health monitoring of road structures by using advanced monitoring techniques, such as unmanned vehicles; non-destructive testing techniques; and artificial intelligence deterioration models, accurate prediction of ongoing damage can be achieved. Accordingly, the automation of these monitoring processes provides significant benefits to both the economy and society by ensuring the longevity and safety of the road structures.

\section{References}

AASHTO 2013. Manual for bridge element inspection. American Association of State Highway and Transportation Officials Washington, DC.

ABDEL-QADER, I., ABUDAYYEH, O. \& KELLY, M. E. 2003. Analysis of edgedetection techniques for crack identification in bridges. Journal of Computing in Civil Engineering, 17, 255-263.

ABDEL-QADER, I., PASHAIE-RAD, S., ABUDAYYEH, O. \& YEHIA, S. 2006. PCAbased algorithm for unsupervised bridge crack detection. Advances in Engineering Software, 37, 771-778.

ADHIKARI, R. S., MOSELHI, O. \& BAGCHI, A. A study of image-based element condition index for bridge inspection. ISARC. Proceedings of the International Symposium on Automation and Robotics in Construction, 2013. Vilnius Gediminas Technical University, Department of Construction Economics \& Property, 1.

AKASHI, K., HASHIMOTO, K., KOIDE, H. \& TOGAWA, M. Development of inspection method using infrared ther-mography technology and its technical consideration. Proceeding of the JSCE 61st Annual Meeting, Kusatsu, Japan, 2006. 1113-1114. 
AMHAZ, R., CHAMBON, S., IDIER, J. \& BALTAZART, V. J. I. T. O. I. T. S. 2016. Automatic crack detection on two-dimensional pavement images: An algorithm based on minimal path selection. 17, 2718-2729.

ANDREW SONNENBERG, P. S. 2014 Australian Bridge Inspection Processes. Small Bridges Conference.

ASCE. 2017 infrastructure report card. 2017. ASCE Reston, VA.

BAIDYA, N., ZHANG, L., MENDIS, P. \& FRAGOMENI, S. Effect of construction sequence in the axial shortening behaviour of composite columns. In: From Materials to Structures: Advancement Through Innovation. The 22nd Australasian Conference on the Mechanics of Structures and Materials, ACMSM 2012, 2013 Sydney, Australia. Taylor \& Francis Group, 55-59.

BHARDWAJ, S. \& MITTAL, A. 2012. A Survey on Various Edge Detector Techniques. Procedia Technology, 4, 220-226.

BHUVANESWARI, P. \& DR, A. B. T. 2014. Edge Detection Techniques in Digital and Optical Image Processing. International Journal of Engineering Research and Applications, Vol 4, Iss 5, Pp 33-37 (2014), 33.

BIONDINI, F. \& FRANGOPOL, D. M. 2016. Life-cycle performance of deteriorating structural systems under uncertainty: Review. Journal of Structural Engineering, 142, 1-17.

CANNY 1986. A Computational Approach to Edge Detection. IEEE Transactions on Pattern Analysis and Machine Intelligence, Pattern Analysis and Machine Intelligence, IEEE Transactions on, IEEE Trans. Pattern Anal. Mach. Intell., 679.

CHAGANTI, V. R. 2017. Edge Detection of Noisy Images using 2-d Discrete Wavelet Transform.

CHANG, P. C., FLATAU, A. \& LIU, S. J. S. H. M. 2003. Health monitoring of civil infrastructure. 2, 257-267.

CHEN, H.-Y. \& CHEN, C. 2016. Determining the emissivity and temperature of building materials by infrared thermometer. Construction and Building Materials, 126, 130-137.

DAVIES, E. R. 2005. Machine vision : theory, algorithms, practicalities / E.R. Davies, Amsterdam ; Boston : Elsevier, c2005.

3rd ed.

ELLENBERG, A., KONTSOS, A., MOON, F. \& BARTOLI, I. 2016. Bridge related damage quantification using unmanned aerial vehicle imagery. Structural Control and Health Monitoring, 1168. 
ELLINGWOOD, B. R. \& MORI, Y. 1993. Probabilistic methods for condition assessment and life prediction of concrete structures in nuclear power plants. Nucl Eng Des, 142, 155-166.

ESTES, A. \& FRANGOPOL, D. 2005. Life Cycle Evaluation and Condition Assessment of Structures. Handbook of Structural Engineering, Second Edition. CRC Press.

EVERETT, T. D., WEYKAMP, P., CAPERS JR, H. A., COX, W. R., DRDA, T. S., HUMMEL, L., JENSEN, P., JUNTUNEN, D. A., KIMBALL, T. \& WASHER, G. A. 2008. Bridge evaluation quality assurance in Europe.

FARRAR, C. R. \& WORDEN, K. 2007. An introduction to structural health monitoring. Philosophical Transactions of the Royal Society of London A: Mathematical, Physical and Engineering Sciences, 365, 303-315.

FHWA. 2013 status of the Nation's highways, bridges, and transit: Conditions \& performance. Rep. to Congress, 2013.

FRANGOPOL, D. M. \& SOLIMAN, M. 2016. Life-cycle of structural systems: recent achievements and future directions. Structure \& Infrastructure Engineering: Maintenance, Management, Life-Cycle Design \& Performance, 12, 1-20.

FU, G. 2005. Inspection and monitoring techniques for bridges and civil structures, Elsevier.

FUJITA, Y., HAMAMOTO, Y. J. M. V. \& APPLICATIONS 2011. A robust automatic crack detection method from noisy concrete surfaces. 22, 245-254.

GERMAN, S., BRILAKIS, I. \& DESROCHES, R. 2012. Rapid entropy-based detection and properties measurement of concrete spalling with machine vision for postearthquake safety assessments. Advanced Engineering Informatics, 26, 846858.

GONZALEZ, R. C. \& WOODS, R. E. 2008. Digital image processing, Upper Saddle River, N.J. : Pearson Prentice Hall, c2008.

3rd ed.

GUCUNSKI, N. \& COUNCIL, N. R. 2013. Nondestructive testing to identify concrete bridge deck deterioration, Transportation Research Board.

GUO, X. \& CHEN, Z. 2015. Lifecycle multihazard framework for assessing flood scour and earthquake effects on bridge failure. ASCE-ASME Journal of Risk and Uncertainty in Engineering Systems, Part A: Civil Engineering, 2, C4015004.

HIASA, S., BIRGUL, R. \& CATBAS, F. N. 2017. Investigation of effective utilization of infrared thermography (IRT) through advanced finite element modeling. Construction and Building Materials, 150, 295-309. 
HOLST, G. C. 2000. Common sense approach to thermal imaging.

IERVOLINO, I., GIORGIO, M. \& CHIOCCARELLI, E. 2013. Gamma degradation models for earthquake-resistant structures. Struct Saf, 45, 48-58.

JAHANSHAHI, M. R., KELLY, J. S., MASRI, S. F. \& SUKHATME, G. S. 2009. A survey and evaluation of promising approaches for automatic image-based defect detection of bridge structures. Structure and Infrastructure Engineering, 5, 455486.

JUNCA, M. \& SANCHEZ-SILVA, M. 2013. Optimal maintenance policy for permanently monitored infrastructure subjected to extreme events. Probabilist Eng Mech, 33, 1-8.

KAFLE, B., ZHANG, L., MENDIS, P., HERATH, N., MAIZUAR, M., DUFFIELD, C. \& THOMPSON, R. 2017a. Monitoring the dynamic behaviour of the Merlynston Creek bridge using interferometric radar sensors and finite element modelling. International Journal of Applied Mechanics, 9, 1750003-1-20.

KAFLE, B., ZHANG, L., MENDIS, P., HERATH, N., MAIZUAR, M., DUFFIELD, C. \& THOMPSON, R. G. 2017b. Monitoring the dynamic behavior of the merlynston creek bridge using interferometric radar sensors and finite element modeling. Int J Appl Mech 9, 1750003-20.

KIM, H., AHN, E., SHIN, M. \& SIM, S.-H. J. S. H. M. 2019. Crack and noncrack classification from concrete surface images using machine learning. 18, 725738.

KOCH, C., GEORGIEVA, K., KASIREDDY, V., AKINCI, B. \& FIEGUTH, P. 2015a. A review on computer vision based defect detection and condition assessment of concrete and asphalt civil infrastructure. Advanced Engineering Informatics, 29, 196-210.

KOCH, C., GEORGIEVA, K., KASIREDDY, V., AKINCI, B. \& FIEGUTH, P. J. A. E. I. 2015b. A review on computer vision based defect detection and condition assessment of concrete and asphalt civil infrastructure. 29, 196-210.

KOH, C. G., ANG, K. K. \& ZHANG, L. 1997a. Effects of repeated loading on creep deflection of reinforced concrete beams. Engineering Structures 19, 2-18.

KOH, C. G., ANG, K. K. \& ZHANG, L. 1997b. Effects of repeated loading on creep deflection of reinforced concrete beams. Eng Struct, 19, 2-18.

LEE, B. Y., KIM, Y. Y., YI, S.-T., KIM, J.-K. J. S. \& ENGINEERING, I. 2013. Automated image processing technique for detecting and analysing concrete surface cracks. 9, 567-577. 
LIHAI, Z., MENDIS, P., WONG CHON, H., FRAGOMENI, S., NELSON, L. \& YILUN, S. 2013. Effects of cyclic loading on the long-term deflection of prestressed concrete beams. Comput Concr 12, 739-754.

LUA, T., MENDIS, P., NGO, T., ZHANG, L., MOHOTTI, D. \& SOFI, M. 2014. Blast studies on bridges - A state-of-the-art review. Electronic Journal of Structural Engineering, 14, 58-70.

MAIZUAR, M., LUMANTARNA, E., SOFI, M., OKTAVIANUS, Y., ZHANG, L., DUFFIELD, C. \& MENDIS, P. 2018. Dynamic behaviour of Indonesian bridges using interferometric radar technology. Electronic Journal of Structural Engineering, 18, 23-29.

MAIZUAR, M., ZHANG, L., MIRAMINI, S., MENDIS, P. \& DUFFIELD, C. 2020. Structural Health Monitoring of Bridges Using Advanced Non-destructive Testing Technique. In: WANG, C., HO, J. \& KITIPORNCHAI, S. (eds.) Lecture Notes in Civil Engineering. Singapore: Springer.

MAIZUAR, M., ZHANG, L., MIRAMINI, S., MENDIS, P. \& THOMPSON, R. 2017a. Detecting structural damage to bridge girders using radar interferometry and computational modelling. Structural Control and Health Monitoring, 24, e1985.

MAIZUAR, M., ZHANG, L., MIRAMINI, S., MENDIS, P. \& THOMPSON, R. G. 2017b. Detecting structural damage to bridge girders using radar interferometry and computational modelling. Struct Control Health Monit, 24, 1-6.

MCCANN, D. \& FORDE, M. 2001. Review of NDT methods in the assessment of concrete and masonry structures. Ndt \& E International, 34, 71-84.

MELCHERS, R. E., LI, C. Q. \& LAWANWISUT, W. 2008. Probabilistic modeling of structural deterioration of reinforced concrete beams under saline environment corrosion. Struct Saf, 30, 447-460.

METNI, N. \& HAMEL, T. 2007. A UAV for bridge inspection: Visual servoing control law with orientation limits. Automation in construction, 17, 3-10.

MOON, H. \& KIM, J. J. P. O. T. T. I. 2011. Intelligent crack detecting algorithm on the concrete crack image using neural network. 1461-1467.

MOORE, M., PHARES, B. M., GRAYBEAL, B., ROLANDER, D. \& WASHER, G. 2001. Reliability of visual inspection for highway bridges, volume I.

NEXCO-WEST "Manual for Maintenance of Road Structures.". West Nippon Expressway Company Limited, Osaka, Japan. 2014 
NISHIKAWA, T., YOSHIDA, J., SUGIYAMA, T., FUJINO, Y. J. C. A. C. \& ENGINEERING, I. 2012. Concrete crack detection by multiple sequential image filtering. 27, 29-47.

OLIVEIRA, H. \& CORREIA, P. L. Identifying and retrieving distress images from road pavement surveys. 2008 15th IEEE International Conference on Image Processing, 2008. IEEE, 57-60.

OMAR, T., NEHDI, M. L. \& ZAYED, T. 2018. Infrared thermography model for automated detection of delamination in RC bridge decks. Construction and Building Materials, 168, 313-327.

PAN, N.-F., LIN, T.-C. \& PAN, N.-H. 2009. Estimating bridge performance based on a matrix-driven fuzzy linear regression model. Automation in construction, 18, 578-586.

PRASANNA, P., DANA, K., GUCUNSKI, N. \& BASILY, B. Computer-vision based crack detection and analysis. Sensors and Smart Structures Technologies for Civil, Mechanical, and Aerospace Systems 2012, 2012. International Society for Optics and Photonics, 834542.

PRESTON, N. 2017. Navigation goes hi-tech. MHD Supply Chain Solutions, 46.

RACKWITZ, R., LENTZ, A. \& FABER, M. 2005. Socio-economically sustainable civil engineering infrastructures by optimization. Struct Saf, 27, 187-229.

RASHIDI, M. \& LEMASS, B. P. 2011. A decision support methodology for remediation planning of concrete bridges.

REHMAN, S. K. U., IBRAHIM, Z., MEMON, S. A. \& JAMEEL, M. 2016. Nondestructive test methods for concrete bridges: A review. Construction and Building Materials, 107, 58-86.

RIASCOS-OCHOA, J., SANCHEZ-SILVA, M. \& AKHAVAN-TABATABAEI, R. 2014. Reliability analysis of shock-based deterioration using phase-type distributions. Probabilist Eng Mech, 38, 88-101.

ROBERT, M. 1982. Science behind thermography-thermal infrared sensing for diagnostics and control. J. Thermosense, 371, 2-9.

RYALL, M. J. 2001. Bridge management, Elsevier.

SÁNCHEZ-SILVA, M., FRANGOPOL, D. M., PADGETT, J. \& SOLIMAN, M. 2016. Maintenance and Operation of Infrastructure Systems: Review. J Struct Eng, $142,1-16$.

SÁNCHEZ-SILVA, M. \& KLUTKE, G.-A. 2016. Reliability and life-cycle analysis of deteriorating systems, Springer. 
SANCHEZ-SILVA, M., KLUTKE, G.-A. \& ROSOWSKY, D. V. 2011. Life-cycle performance of structures subject to multiple deterioration mechanisms. Struct Saf, 33, 206-217.

SÁNCHEZ-SILVA, M. \& RACKWITZ, R. 2004. Socioeconomic implications of life quality index in design of optimum structures to withstand earthquakes. J Struct Eng, 130, 969-977.

SOFI, M., ZHANG, L., MENDIS, P. \& BAWEJA, D. Early age concrete creep: Using model B3 prediction. In: Incorporating Sustainable Practice in Mechanics of Structures and Materials The 21st Australian Conference on the Mechanics of Structures and Materials, 2011. Taylor \& Francis Group, 267-272.

SONNENBERG, A. Australian bridge inspection processes. Australian Small Bridges Conference, 5th, 2012, Surfers Paradise, Queensland, Australia, 2012.

STEIN, S. M., YOUNG, G. K., TRENT, R. E. \& PEARSON, D. R. 1999. Prioritizing Scour Vulnerable Bridges Using Risk. J Infrastruct Syst 5, 95-101.

TSAI, Y.-C., KAUL, V. \& MERSEREAU, R. M. 2010. Critical assessment of pavement distress segmentation methods. Journal of Transportation Engineering, 11.

VICROADS 2014. Road strcutre inspection manual

VINES, G. 2010. National Trust Study of Victoria's Concrete Road Bridges. Report for the National.

WANG, H., HUANG, H., FENG, Y., ZHANG, D. J. A.-A. J. O. R. \& UNCERTAINTY IN ENGINEERING SYSTEMS, P. A. C. E. 2018. Characterization of crack and leakage defects of concrete linings of road tunnels in China. 4, 04018041.

WASHER, G., FENWICK, R., BOLLENI, N. \& HARPER, J. 2009. Effects of environmental variables on infrared imaging of subsurface features of concrete bridges. Transportation Research Record: Journal of the Transportation Research Board, 107-114.

YAMAGUCHI, T. \& HASHIMOTO, S. 2010. Fast crack detection method for large-size concrete surface images using percolation-based image processing. Machine Vision and Applications, 21, 797-809.

YAMAGUCHI, T., NAKAMURA, S., SAEGUSA, R. \& HASHIMOTO, S. 2008. Imagebased crack detection for real concrete surfaces. IEEJ Transactions on Electrical and Electronic Engineering, 3, 128-135.

YANG, Y. \& KLUTKE, G.-A. 2000. Improved inspection schemes for deteriorating equipment. Probab Eng Inform Sc, 14, 445. 
YEHIA, S., ABUDAYYEH, O., NABULSI, S. \& ABDELQADER, I. J. J. O. B. E. 2007. Detection of common defects in concrete bridge decks using nondestructive evaluation techniques. $12,215-225$.

ZHANG, L., MAIZUAR, M., MENDIS, P., DUFFIELD, C. \& THOMPSON, R. 2016a. Monitoring the dynamic behaviour of concrete bridges using non-contact sensors (IBIS-S). Applied Mechanics and Materials, 846, 225-230.

ZHANG, L., MENDIS, P., HON, W. C., FRAGOMENI, S., LAM, N. \& SONG, Y. 2013. Effects of cyclic loading on the long-term deflection of prestressed concrete beams. Computers and Concrete, 12, 377-392.

ZHANG, L., XU, W., ZHU, L., YUAN, X. \& ZHANG, C. Study on Pavement Defect Detection Based on Image Processing Utilizing UAV. Journal of Physics: Conference Series, 2019. IOP Publishing, 042011.

ZHANG, L., YANG, F., ZHANG, Y. D. \& ZHU, Y. J. Road crack detection using deep convolutional neural network. 2016 IEEE international conference on image processing (ICIP), 2016b. IEEE, 3708-3712.

ZOU, Q., CAO, Y., LI, Q., MAO, Q. \& WANG, S. J. P. R. L. 2012. CrackTree: Automatic crack detection from pavement images. 33, 227-238. 


\section{University Library}

\section{- M M N E R VA A gateway to Melbourne's research publications}

Minerva Access is the Institutional Repository of The University of Melbourne

Author/s:

Zhang, L;Herath, N;Raja, BNK;Chen, S;Miramini, S;Duffield, C

Title:

Automation in structural health monitoring of transport infrastructure

Date:

2021-01-01

Citation:

Zhang, L., Herath, N., Raja, B. N. K., Chen, S., Miramini, S. \& Duffield, C. (2021). Automation in structural health monitoring of transport infrastructure. Advances in 21st Century Human Settlements, pp.141-172. Springer Singapore.

Persistent Link:

http://hdl.handle.net/11343/292050 